\title{
Connecting carbon porosity with dispersibility and friability
}

John Texter, $1,{ }^{*}$ Li Zhao, ${ }^{2,3,+}$ Pei-Wen Xiao, ${ }^{3}$ Fernando Pérez Caballero, ${ }^{2}$ Bao-Hang Han, ${ }^{3}$ and Maria-Magdalena Titirici, ${ }^{2, \xi^{*}}$

${ }^{1}$ School of Engineering Technology, Eastern Michigan University, Ypsilanti, MI 48197, USA

${ }^{2}$ Colloid Chemistry Department, Max Planck Institute for Colloids and Interfaces 14424 Potsdam, Germany

${ }^{3}$ National Center for Nanoscience and Technology,11 Beiyitiao Zhongguancun, Beijing 100190, China

${ }^{\dagger}$ (present address)National Center for Nanoscience and Technology,11 Beiyitiao Zhongguancun, Beijing 100190, China

$\S$ (present address) School of Engineering and Materials Science \& Materials Research Institute, Queen Mary University of London, Mile End Road, London, E1 4NS, UK

*Corresponding authors:

John Texter, Tel: 1734487 4587; E-mail: jtexter@emich.edu

Maria-Magdalena Titirici, Tel: 44 (0)20 7882 6272; E-mail: m.m.titirici@qmul.ac.uk

(C) 2016. This manuscript version is made available under the Elsevier user license http://www.elsevier.com/open-access/userlicense/1.0/ 


\begin{abstract}
Chitosan, glucosamine, a glucose-melamine mixture, a glucose polyvinylpyrrolidone mixture, and a glucose poly(vinylpyrrolidone-co-vinylimidazole) mixture are examined in a hydrothermal carbonization and calcining process to investigate effects of nitrogen additives on incorporation of nitrogen into the carbon products and the effects of such additives on morphology and porosity. The resulting calcined hydrothermal carbons are examined for their aqueous dispersibility using a nanolatex (NL) stabilizer based on an ionic liquid imidazolium acrylate monomer. Sonication of water, nanolatex, and carbon mixtures shows that ease of dispersion and friability increase with carbon porosity. This is the first report connecting friability with porosity on $\mu \mathrm{m}$ to $\mathrm{nm}$ length scales. Scanning electron microscopy of carbon dispersions in excess NL suggests adsorption of NL from suspension is random and irreversible, and accompanied by conformational equilibration and spreading. Thin films made from aqueous dispersions and from sediments obtained by centrifugation of such dispersions exhibit electrical and thermal conductivities that can be understood in terms of how the carbon particles pack in a gravitational or centrifugal field. The most porous carbon is found to produce an optical extinction in the visible on the order of that exhibited by single wall carbon nanotubes. Carbon produced hydrothermally from glucose and melamine appears to be a layered material that is electrically insulating while appreciably thermally conducting.
\end{abstract}




\section{Introduction}

Hydrothermal carbonization [1-4] is a gradual technique for turning sugars, polysaccharides, and vegetable matter sequentially into top soil ( $2 \mathrm{~h}$ ), peat (4-6 h), brown coal (12-16 h), and into advanced carbon materials in addition to fuel stocks [5,6]. Such advanced materials are often given additional thermal treatments at higher temperature in the presence of various gases and materials. The degree of carbonization increases with time in the presence of excess water under autoclaving conditions of 180 to $200{ }^{\circ} \mathrm{C}$. This reaction is exothermic, and this excess heat can be used to sustain this carbonization reaction [2].

Hydrothermal conversions of biomass to produce biofuels have been reviewed [7], although the treatments covered range from $200-600{ }^{\circ} \mathrm{C}$, higher than the $180-200{ }^{\circ} \mathrm{C}$ processes with which we begin. The production of ethanol from sugar cane and corn and the transesterification of triglycerides to produce biodiesel are discussed, and biomass conversions at high temperatures in the presence of supercritical water are also examined. The chemistry of hydrothermal water with simple biomass components (derived from algae) has been reviewed recently [8,9]. The initiation and rebirth of converting biomass to various types of useful hydrothermal carbons at temperatures below $200{ }^{\circ} \mathrm{C}$ has been reviewed by Titirici and Antonietti [4]. They examine how carbonaceous advanced materials may be derived from pure carbohydrates as well as from biomass, and they illustrate applications in metal oxide nanostructures, catalysts, water purification, and $\mathrm{CO}_{2}$ sequestration. They also make the point that hydrothermal carbonization is a dehydration process that is exothermic.

Since the rebirth of HTC studies beginning with Huang and co-workers in 2001 [10], highly porous carbon derived by hydrothermal carbonization has been found useful for several types of advanced carbon material applications. Mesoporous HTC derived from various sources has been described, including naturally occurring chitin $[11,12]$, glucosealbumin and glucose-ovalbumin mixtures [13,14], xylose, glucose, sucrose, and starch [15], oak leaves [16], hemp [17], and algae [18]. The use of hard templating approaches to produce porous HTC using silica, alumina, and other "hard" porogens has been demonstrated [19]. HTC materials have also been used as sacrificial templates for other 
advanced materials [20,21]. Other important applications include carbon dioxide sequestration [22-25], separations [26-36], catalysis [37-45], supercapacitor fabrication [46-49], and battery electrodes [50-55].

In this study we examine substrate-nitrogen additive effects on the morphology and dispersibility of HTC obtained from a series of saccharides and derivatives. Furfural, glucose, glucosamine, and chitosan are used as primary substrates. Molecular and polymeric sources of nitrogen are examined as additives. Chitosan (a homopolymer of glucosamine) and glucosamine were chosen for study because of their equivalent nitrogen contents, wherein their nitrogen is incorporated as a primary amine in these starting materials. A mixture of glucose and melamine was chosen to see how thermal processing may or may not lead to nitrogen incorporation when a very high level of precursor nitrogen is present. Polymers of various types have been shown to affect hydrothermal carbonization, and so glucose was mixed with polyvinylpyrrolidone (PVP) to examine low nitrogen precursor concentration. Finally, furfural, a hydrothermal carbonization product of glucose and other saccharides, was mixed with an equal weight of a copolymer of vinylpyrrolidone and vinyl imidazole to examine how this polymer influenced nitrogen incorporation and morphology.

Nanolatexes $20-30 \mathrm{~nm}$ in diameter derived from a reactive ionic liquid surfactant acrylate and methylmethacrylate (MMA) [56] have been shown to be effective aqueous dispersants for nanocarbons including SWCNT [57], MWCNT [58,59], WC [58,60], graphene $[59,61]$ and a particular hydrothermal carbon $[6,62]$. This dispersing activity can be assigned to the affinity of the imidazolium cation for graphenic surfaces [61]. We utilize this same nanolatex in this study.

\section{Experimental section}

\subsection{Materials}

Chitosan (medium molecular weight with $80 \pm 5 \%$ of the $N$-acetyl groups hydrolyzed to amine), $\mathrm{D}(+)$-glucose ( $\alpha$-D-glucopyranose), melamine (1,3,5-triazine-2,4,6-triamine), furfural (furan-2-carbaldehyde), and D(+)-glucosamine hydrochloride ( $>99.0 \%$, HPLC; 3amino-6-(hydroxymethyl)oxane-2,4,5-triol) were purchased from Sigma-Aldrich and used without further purification. Luvitec K60 (obtained from BASF) was a 34-36\% by weight 
solution of poly(vinyl pyrrolidone) (PVP) in water with a pH of 7-9 and less than $0.03 \%$ (w/w) nonvolatile residue. Luvitec VPI $55 \mathrm{~K} 72 \mathrm{~W}$ (also obtained from BASF) is a nominally random copolymer of vinyl pyrrolidone and vinyl imidazole. Water used for hydrothermal treatment was deionized.

\subsection{Preparation of HTC}

The mixtures listed in Table 1 were prepared at a total weight of $20 \mathrm{~g}$, placed in glass vials inside a PTFE lined autoclave, and heated at $180{ }^{\circ} \mathrm{C}$ for $20 \mathrm{~h}$. After this hydrothermal treatment, the autoclave was cooled in a cold-water bath. The carbonaceous solids were removed from the glass vials, filtered, and washed with distilled water several times followed by drying in a vacuum oven at $80^{\circ} \mathrm{C}$ overnight. Afterwards, in order to improve the level of structural order, further high temperature $\left(750^{\circ} \mathrm{C}\right)$ treatment was performed in an oven under $\mathrm{N}_{2}$ flow. Samples were heated from room temperature to $750{ }^{\circ} \mathrm{C}$ over $6 \mathrm{~h}$, held at $750^{\circ} \mathrm{C}$ for $4 \mathrm{~h}$, and allowed to cool to room temperature. These calcined samples are referred to as: Chitosan; GlucNH 2 ; GlucMel; GlucK60; FurVPVI. Elemental analysis of C, H, and $\mathrm{N}$ was done for each sample using combustion analysis.

\subsection{Nanolatex stabilizer}

1-(11-Acryloyloxyundecyl)-3-methyl imidazolium bromide, ILBr, was synthesized as previously described [63,64]. Nanolatexes were prepared by microemulsion polymerization initiated at $60^{\circ} \mathrm{C}$ with AIBN (azobisisobutyrylcyanide) and composed of $4 \%$ ILBr, 2.67\% MMA (methyl methacrylate), and the balance water. After polymerization the nanolatexes were concentrated by ultrafiltration to $16-18 \%$ solids [56] for use in formulating dispersions.

\subsection{Preparation of HTC dispersions}

After grinding HTC samples with mortar and pestle, HTC samples and aqueous nanolatex were combined in a vial to a total of $10 \mathrm{~g}$ and sonicated. HTC samples (200 $\mathrm{mg}$ ) were combined with $9.8 \mathrm{~g}$ nanolatex suspension (18\% solids). Initial low power sonication was done with a cleaning bath, Branson B300 for one hour. Higher power sonication was done with a (SONICS Vibra Cell, Model VC 30 (Newtown, CT) using a "micro" tip having a diameter of about $3 \mathrm{~mm}$. The net compositions were $2 \%(\mathrm{w} / \mathrm{w})$ HTC and $16.9 \%(\mathrm{w} / \mathrm{w})$ nanolatex. Sonication intensities of $50 \%$ and $100 \%$ amplitude (of maximum power) were 
used to study sonication intensity effects. Typically sonication was done at $50 \%$, and after reaching a plateau in apparent optical density versus sonication time, the intensity was increased to $100 \%$ to see if further improvement could be obtained. The dispersion temperature during sonication was kept below $50^{\circ} \mathrm{C}$.

Apparent optical densities were checked as a function of high power sonication time. The zero time optical density was that obtained for the dispersion after sonicating in a low power ultrasonic cleaning bath. Apparent optical densities at $500 \mathrm{~nm}$ were obtained by (gravimetrically) diluting $30 \mu \mathrm{L}$ to $70 \mu \mathrm{L}$ aliquots sufficiently to get an optical absorption value between 0.1 and 1.0. This measured optical density was then multiplied by the dilution factor to get an apparent optical density at $500 \mathrm{~nm}$.

\subsection{Preparation of dispersion films}

Dispersion aliquots $(\sim 1 \mathrm{~g})$ were placed in an annular ring inside $50 \mathrm{~mL}$ polypropylene centrifuge-tube caps (for freeze fracture SEM [scanning electron microscopy], dielectric spectroscopy, and thermal diffusivity measurements) or in rectangular machined molds in the top of a Teflon block (for in-plane conductivity measurements) to sediment and dry for one to two days. These castings were removed intact for examination by various methods. Freeze fracture samples were made by chilling in liquid nitrogen before breaking the films for SEM analysis. These films were cured by drying at ambient, and the bottom sides always presented as matte and the top surfaces always appeared shiny. For conductivity measurements these films were equilibrated $24 \mathrm{~h}$ at $44 \%$ relative humidity in a desiccator over saturated aqueous $\mathrm{K}_{2} \mathrm{CO}_{3}$.

\subsection{Instrumentation}

Nitrogen adsorption and desorption isotherms were measured at $77 \mathrm{~K}$ with a Quantachrome Quadrasorb adsorption instrument (Quantachrome, Germany). The Brunaer-Emmett-Teller (BET) [65] and density functional theory (DFT) [66] methods were used for the surface area determinations and pore size distribution calculations, respectively. Vis/UV absorbance measurements were made using a Jasco V-530 spectrometer. Scanning electron microscopy (SEM) was done with an Hitachi S3400N SEM (Hitachi Instruments, Pleasantville, CA). Nitrogen gas adsorption was done using a Quantachrome apparatus (Quantachrome, Germany). A TA Instruments (New Castle, 
Delaware, USA) Q2000 differential scanning calorimeter (DSC) was used for characterizing heat capacity and a Q200 thermal gravimetric analyzer (TGA) was used for quantifying decomposition as a function of temperature. A Netsche (Selb, Germany) LFA 447 xenon flash thermal diffusivity instrument was used for measuring thermal diffusivity. Infrared (IR) spectra were obtained by using a Spectrum One Fourier transform infrared (FT-IR) spectrometer (Perkin-Elmer Instruments Co. Ltd., USA). Samples were dispersed in $\mathrm{KBr}$ pellets. X-ray photoelectron spectroscopy (XPS) surface experiments were done using a Thermo Scientific ESCALAB 250Xi with a monochromatic Al source (hv=1486.6 eV, $15 \mathrm{kV}$ primary energy, $30 \mathrm{~mA}$ emission intensity), with an analysis area of $500 \times 500 \mu \mathrm{m}^{2}$ (Thermo Fisher, USA).

A Novocontrol Technologies GmbH (Montabauer, Germany) broadband dielectric spectrometer, Concept 80 System, was used for permittivity, dielectric loss, and throughplane electrical conductivity measurements. Surface conductivities (in-plane) were measured using a four-electrode (Pt wire) probe and a Gamry Instruments (Warminster, PA, USA) impedance spectroscopy system. The two inner parallel electrodes were used to measure voltage and phase shift and the two outer electrodes were used to measure current at frequencies varying form $1 \mathrm{~Hz}$ to $100 \mathrm{kHz}$. Current amplitudes of 0.5 to $10 \mu \mathrm{A}$ were used. Because of the relatively high conductivities, Nyquist plots were discarded and values were taken at $1 \mathrm{~Hz}$. The films used for these surface measurements were rectangular films cast in Teflon molds. Conductivities were calculated from the measurements using the equation

$$
=\frac{d}{R A}
$$

where $d$ is the separation distance of the inner two electrodes, $A$ is the cross-sectional area of the film (width $\times$ thickness), and $R$ is the measured resistance.

\section{Results and discussion}

\subsection{HTC materials}

Chitosan is derived from chitin, poly( $\beta-(1-4)-N$-acetyl-D-glucosamine (with $\sim 10 \%$ of the $N$-acetyl groups hydrolyzed), the primary carbohydrate in exoskeletons of crustaceans (e.g., crayfish, shrimp, lobsters) by further hydrolysis of $N$-acetyl moieties to an extent of 80 
Table 1 - HTC precursor compositions (and empirical formulae for non-aqueous components)

\begin{tabular}{|c|c|c|c|}
\hline Sample & Precursor Composition & $\begin{array}{c}\text { Empirical } \\
\text { Formula }\end{array}$ & $\% \mathrm{~N}$ \\
\hline Chitosan & $10 \%$ Chitosan, $90 \%$ water & $\mathrm{C}_{6.4} \mathrm{H}_{13.4} \mathrm{NO}_{5}$ & 7.6 \\
\hline GlucNH $_{2}$ & $10 \%$ Glucosamine, $90 \%$ water & $\mathrm{C}_{6} \mathrm{H}_{13} \mathrm{NO}_{5}$ & 7.8 \\
\hline GlucMel & $\begin{array}{c}10 \% \text { Glucose, } 10 \% \text { melamine, } 80 \% \\
\text { water }\end{array}$ & $\mathrm{C}_{5.1} \mathrm{H}_{10.3} \mathrm{~N}_{8.6} \mathrm{O}_{6}$ & 41.8 \\
\hline GlucK60 & $\begin{array}{c}10 \% \text { Glucose, } 2 \% \text { K60 (BASF PVP), } \\
88 \% \text { water }\end{array}$ & $\mathrm{C}_{7.9} \mathrm{H}_{14.9} \mathrm{~N}_{0.3} \mathrm{O}_{6.3}$ & 2.0 \\
\hline FurVPVI & $\begin{array}{l}\text { 10\% Furfural; 10\% 72W (BASF } \\
\text { poly(vinyl pyrrolidone-co-vinyl } \\
\text { imidazole), } 80 \% \text { water }\end{array}$ & $\mathrm{C}_{10.3} \mathrm{H}_{10.6} \mathrm{~N}_{1.3} \mathrm{O}_{2.4}$ & 9.5 \\
\hline
\end{tabular}

$\pm 5 \%$. It is a copolymer of glucosamine and $N$-acetyl-glucosamine, and is about $7.6 \%$ nitrogen. Glucosamine, GlucNH $\mathrm{H}_{2}$, is substituted in the 5-position with an $\mathrm{NH}_{2}$ group and is $7.8 \%$ nitrogen by weight. Our equal weight glucose and melamine mixture, GlucMel, represents the most heavily nitrogen-containing composition examined in this study, and is about $41.8 \%$ nitrogen. The GlucK60 sample is mostly glucose with a small amount of nitrogen coming from inclusion of a polyvinylpyrrolidone homopolymer, and is about $2.0 \%$ by weight nitrogen. The fifth composition is derived from furfural and an equal weight of a copolymer of vinylpyrrolidone and vinylimidazole, and is about $9.5 \%$ by weight nitrogen.

These five compositions, described in Table 1, were prepared to a total weight of about $20 \mathrm{~g}$, and sealed in glass vials for overnight treatment at $180{ }^{\circ} \mathrm{C}(20 \mathrm{hrs})$, removed, filtered, and dried. The gravimetric yields after hydrothermal carbonization, washing, and drying ranged from $25 \%$ for GlucNH $\mathrm{N}_{2}$ to about $30 \%$ to $34 \%$ for the other materials and mixtures. The fractions of soluble components remaining in the excess water were not measured. Subsequent calcination at $750{ }^{\circ} \mathrm{C}$ under nitrogen yielded $50 \%$ to $60 \%$ for all samples. While calcination yields were not as small as hydrothermal treatment, major 
morphology changes occurred, except for GlucNH $\mathrm{N}_{2}$ (discussed later). These losses are as good as or better than those of pure glucose or of starch in the absence of catalyst, where only $18 \%$ to $30 \%$ yields are obtained in the hydrothermal step [67]. About $50 \%$ by weight is lost simply upon dehydration under hydrothermal carbonization, and further losses are incurred by formation of water soluble species such as HMF and levulinic acid [15]. Even lower yields for xylose and fructose have been reported by Suh and co-workers [68].

The resulting HTC materials were subjected to $\mathrm{C}, \mathrm{H}$, and $\mathrm{N}$ elemental analysis by combustion analysis, and the results are summarized in Table 2. Not surprisingly, the GlucMel sample incorporates the highest amount of nitrogen (41.8\% of initial solids) and

Table 2 - Elemental composition and empirical formulae of HTC materials calcined at $750^{\circ} \mathrm{C}^{\mathrm{a}}$

\begin{tabular}{|c|c|c|c|c|c|}
\hline HTC Precursor & $\% \mathrm{C}$ & $\% N$ & $\% \mathrm{H}$ & $\mathrm{C} / \mathrm{N}$ & Empirical Formula \\
\hline Chitosan & 79.2 & 9.1 & 1.51 & 8.8 & $\mathrm{C}_{6.6} \mathrm{H}_{1.5} \mathrm{~N}_{\mathbf{0 . 6 5}} \mathrm{O}_{0.64}$ \\
\hline GlucNH$_{2}$ & 81.6 & 6.6 & 1.43 & 12.4 & $\mathrm{C}_{6.8} \mathrm{H}_{1.4} \mathrm{~N}_{0.47} \mathrm{O}_{0.65}$ \\
\hline GlucMel & 67.7 & 21.8 & 1.61 & 3.1 & $\mathrm{C}_{5.6} \mathrm{H}_{1.6} \mathrm{~N}_{1.6} \mathrm{O}_{0.56}$ \\
\hline GlucK60 & 92.7 & 2.8 & 1.15 & 33.1 & $\mathrm{C}_{7.7} \mathbf{H}_{1.2} \mathbf{N}_{0.2} \mathbf{O}_{0.2}$ \\
\hline FurPVPVI & 83.9 & 8.8 & 1.35 & 9.5 & $\mathrm{C}_{7.0} \mathrm{H}_{1.4} \mathrm{~N}_{0.63} \mathrm{O}_{0.37}$ \\
\hline
\end{tabular}

${ }^{\mathrm{a}} \mathrm{C}, \mathrm{H}$, and $\mathrm{N}$ compositions determined by combustion analysis.

the GlucK60 material incorporates the least ( $2.0 \%$ of initial solids). These materials can be listed in the following decreasing order of nitrogen incorporation (Table 2):

$$
\text { GlucMel }>\text { Chitosan } \sim \text { FurVPVI }>\text { GlucNH }_{2}>\text { GlucK60. }
$$

The incorporated nitrogen tracks the proportion of nitrogen added prior to hydrothermal treatment. The relative amount of oxygen remaining appears to decrease in the order:

$$
\text { GlucNH }_{2} \sim \text { Chitosan }>\text { GlucMel }>\text { FurVPVI }>\text { GlucK60. }
$$

In this series the GlucK60 appears to be the most carbonaceous after hydrothermal and activated treatment. 
The nitrogen content of these calcined HTC materials is relatively high, as shown in Table 2. This indicates the successful and stable incorporation of nitrogen into the carbonized matrix via hydrothermal carbonization.

\subsection{Effects of treatments on morphology}

Two of our materials, Chitosan and $\mathrm{GlucNH}_{2}$, have been studied earlier with respect to morphological effects of hydrothermal treatment followed by anaerobic heating at $750{ }^{\circ} \mathrm{C}$ (calcining) [69,70]. Simple sugars tend to form dense phase carbon spheres in the halfmicron to multi-micron diameter range during/after hydrothermal treatment [71,72]. This spherical morphology is a natural consequence of forming amorphous phases of both inorganic and organic matter, and is due to a natural Gibbs free energy drive to minimize the specific surface area of the material. Spheres provide the geometric shape that yields the lowest specific surface area $\left(\mathrm{m}^{2} / \mathrm{g}\right)$ of any regular shape. Chitosan has been observed to form networks of very small particles ( $\sim 40-50 \mathrm{~nm}$ diameter) forming connected networks and exhibiting significant aggregation, but nonetheless showing some degree of microporosity formation. Similarly, $\mathrm{GlucNH}_{2}$ forms dense aggregates of small particles as well as some microporisity on hydrothermal carbonization. Loss of specific surface area indicates chemical coalescence, an important step along a path leading to dense (bulk) phase formation.

SEM of these calcined $\left(750^{\circ} \mathrm{C}\right)$ HTC materials are illustrated in Fig. 1, and the morphologies illustrated vary dramatically. These views show that post carbonization at $750{ }^{\circ} \mathrm{C}$ induces in each material, with the exception of $\mathrm{GlucNH}_{2}$, dramatic morphology transformation. An expected morphology obtained by simple sugars during hydrothermal carbonization is that of solid or porous microspheres. Such spheres obtained from glucose are illustrated in the supplementary material (Fig. S1) and have been previously reported [70]. The chitin-derived sample, Chitosan, is the only natural product or polysaccharide in our study. It too is transformed by hydrothermal carbonization into particles $(\sim 50 \mathrm{~nm}$ diameter) forming a dense agglomerated mass (Fig. S2). Upon calcination at $750{ }^{\circ} \mathrm{C}$ these nanoparticles transform into dense solid particles orders of magnitude larger in dimension, as shown in the SEM of Fig. 1. A driving force for this dramatic change in morphology is a 
very high loss of Gibbs surface free energy that is given up by further densification during calcination of this material.

The GlucNH$H_{2}$ material after hydrothermal carbonization exhibits microporosity and macroporosity (Fig. S2) deriving from polydisperse particles. These particles range in size from less than $50 \mathrm{~nm}$ in diameter to spheroidal and plate-like particles having $0.5 \mu \mathrm{m}$ to 1 $\mu \mathrm{m}$ dimensions. On calcination these particles transform into larger platelet particles having dimensions of $10^{\prime}$ s of $\mu \mathrm{m}$ to sub- $\mu \mathrm{m}$ platelets. Again, a significant driving force is lowering of the total Gibb's surface free energy by a significant loss in specific surface area (area per g carbon).

The after calcination morphology of $\mathrm{GlucNH}_{2}$ differs greatly from that obtained for Chitosan (Fig. 1), and retains a high fraction of very small platelets in addition to platelets exceeding $10 \mu \mathrm{m}$ in lateral dimension, similar to that obtained after hydrothermal carbonization. These differences suggest a marked effect of the linear polymeric structure of the Chitosan. A minor amount of $\mathrm{N}$-acetyl moieties remaining in the Chitosan, the low $\mathrm{pH}$ nature of the $\mathrm{GlucNH}_{2}(\mathrm{HCl})$ composition, or some combination of these factors result in measurable differences in specific surface area and porosity (discussed below).

The FurVPVI material after calcination (Fig. 1) also has a morphology similar to that of the Chitosan sample. FurVPVI also exhibits an after carbonization composition that is very close to that of Chitosan, although the starting composition is more dissimilar to Chitosan than is that for GlucNH$H_{2}$. Furfural, when subjected to hydrothermal carbonization in the presence of poly(vinylimidazole), PVI, forms dense aggregates of nanoparticles $<50$ nm diameter similarly as Chitosan (Fig. S2). We attribute the similarity of FurVPVI to Chitosan as primarily due to the linear copolymer doping effects resulting from mixing PVPI with furfural.

The GlucMel material exhibits quite a different morphology after hydrothermal carbonization that appears somewhat fibrous and somewhat layer-like (Fig. S2). It has the highest pre- and post-carbonization nitrogen content of any of the samples. While the high nitrogen content and layer morphology after hydrothermal treatment and after calcination distinguishes this material from the others, it may in part be graphitic, and the postcarbonization stoichiometry remaining after calcination at $750{ }^{\circ} \mathrm{C}$ does not suggest a high 
carbon nitride component. The SEM of Fig. 1, however, suggests transformation of material into three morphologies: (1) very small and thin platelets; (2) an intermediate phase of multi-micron spheroidal particles; (3) multi-micron dimension platelets. It appears that spheroids may decompose in part to yield the smaller platelets. Larger fields of view are provided in the SI in Fig. S1. 


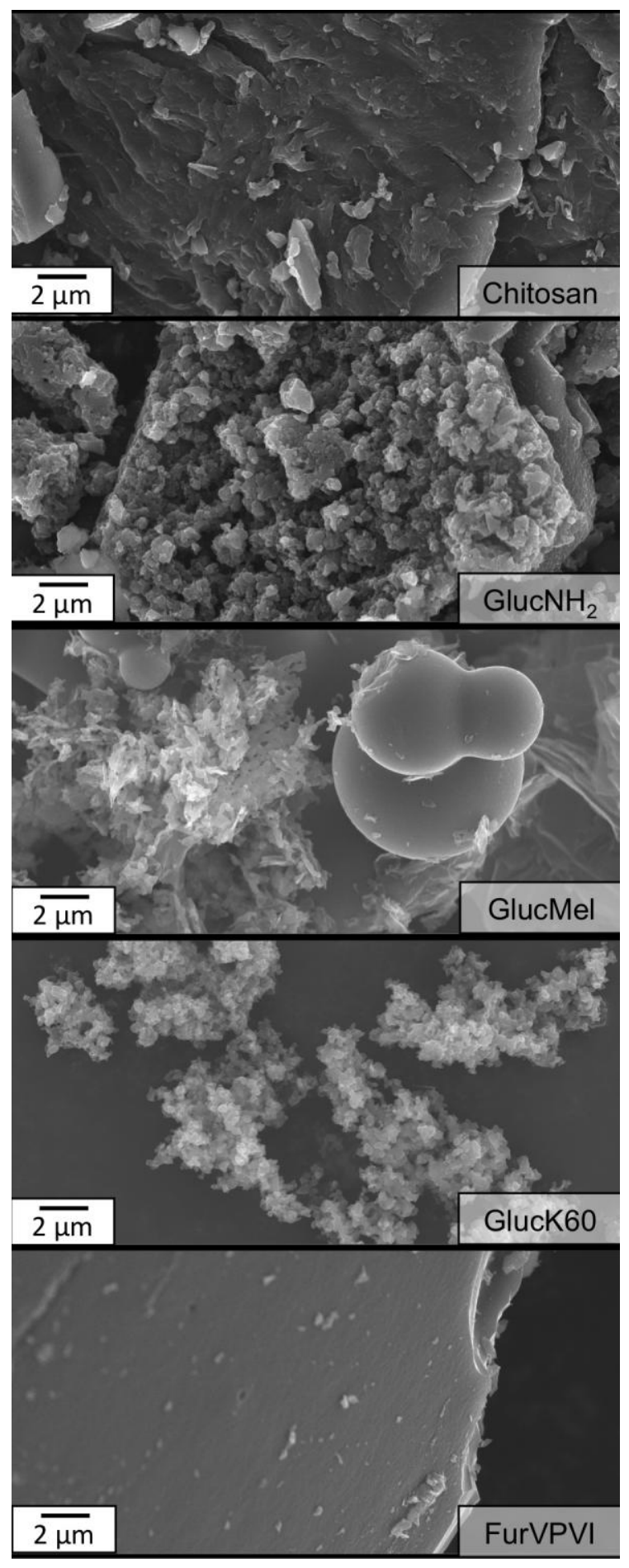

Fig 1 - SEM of hydrothermal carbon samples after hydrothermal treatment followed by higher temperature heating under nitrogen: (top to bottom) Chitosan; GlucNH2; GlucMel; GlucK60; FurVPVI. 
The GlucK60 material exemplifies a particulate-network morphology (Fig. S2) after hydrothermal carbonization that comprises $100 \mathrm{~nm}$ to $150 \mathrm{~nm}$ particulates aggregated in 3D chain fragments. This material appears to exhibit mesoporosity emanating from particle-packing interstices. After calcination at $750{ }^{\circ} \mathrm{C}$ these nanoparticles transform into platelets structures having micron and smaller dimensions (Fig. 1, Fig. S3). The spheroidal particulates formed by hydrothermal carbonization (Fig. S2) appear to transform into larger but much thinner platelets on calcination

Collectively these precursors all appear to form particulates during hydrothermal treatment with the exception of GlucMel, and GlucMel appears to form particulate intermediates during calcination. The formation of relatively dense phases of Chitosan, FurVPVI, and GlucNH${ }_{2}$ can be rationalized as being controlled by minimization of Gibbs surface energy by loss of such free energy to the respective bulk cohesion energies. The GlucMel and GlucK60 materials, however, appear to evolve to higher specific surface energy materials, suggesting that the layer or bulk structures formed dominate thermodynamically over the apparently increasing specific surface areas created by platelet formation.

\subsection{Effects of treatments on chemical structure}

Glucose transformations under similar conditions, in addition to providing a good reference for examining morphology transformations discussed above, also serves as a good reference material for discussing chemical transformations. Glucose has been discussed quite thoroughly in the literature, so we summarize the main points of importance [70]. The main transformations operating on glucose during $180{ }^{\circ} \mathrm{C}$ treatment, while it undergoes dehydration, consist mainly of generating hydroxymethyl furfural (HMF), which converts to a small (minor) levulinic acid fraction on rehydration of HMF and then polymerizes (major) to make a solid phase of oxygenated hydrothermal carbon. This phase initially has a ratio of furanic groups to arene groups greater than four [73]. Higher temperature calcination gradually converts this oxygenated brown coal into successively higher weight fractions of poly(aromatic hydrocarbons) (PAH) and on to graphitic carbon, while retaining some oxygenated species, mainly hydroxyl groups on the periphery of aromatic clusters. During this sequence the carbon content increases from $40 \%$ in glucose 
to $67 \%$ after HTC treatment, and further to $90 \%$ to $94 \%$ after carbonization at $750{ }^{\circ} \mathrm{C}$. After this $750{ }^{\circ} \mathrm{C}$ treatment the distribution of carbon moieties as resolved by C1s XPS is approximately 84\% graphitic and carbon-carbon double bond (285 eV), about 9\% C-0 $(286.5 \mathrm{eV}), 4 \% \mathrm{C}=0(288 \mathrm{eV})$, and 3\% carbonate $(290.3 \mathrm{eV})$. The main high temperature product is graphitic carbon clusters that also exhibit typical layering, although the diffraction peaks exhibit considerable amorphous broadening. It is believed that most of the small amount of oxygen remaining populates cluster edges as hydroxyl groups.

We will see later on that these five types of materials represent a diverse set of compositions, and turn out to be very useful for establishing variations in porosity for this dispersion study. An important auxiliary issue is to try to understand the chemical transformations that occur during hydrothermal and calcination processing. Chemical compositions are illustrated for Chitosan and its precursors as well as for GlucNH $\mathrm{NH}_{2}$ and its precursors, and these data are summarized in the SI (Table S1 and Fig. S3). XPS spectra of the other materials of this study are illustrated in Fig. 2. To facilitate discussion of nitrogen incorporation, pyridonic, pyridinic, and aromatic nitrogen XPS N1s spectra refer to the structures [74] shown in Scheme 1.

The chemical transformations previously examined $[69,70]$ for Chitosan and $\mathrm{GlucNH}_{2}$ can be summarized as follows on the basis of elemental analyses (Tables 1 and 2) and XPS spectra (Table S1 and Fig. S4). The Chitosan starting material exhibited an intense C1s XPS resonance at $286.1 \mathrm{eV}$ for carbon bonded to hydroxyl or alkoxy and weaker resonances centered at $286.4 \mathrm{eV}$ and $287.9 \mathrm{eV}$ assigned, respectively, to aliphatic carbon and C-O-C groups. It also exhibited an intense N1s signal at $399.3 \mathrm{eV}$ characteristic of its amine nitrogen. Upon hydrothermal carbonization, some aromatic carbon signal was indicated by XPS spectra at $284.6 \mathrm{eV}$ with some residual carbonyl signal at $287.3 \mathrm{eV}$ and residual carboxyl at $288.9 \mathrm{eV}$. The amine N1s disappears and is replaced with a resonance at 402.1 $\mathrm{eV}$ characteristic of quaternary nitrogen, showing nitrogen incorporation into the carbon lattice, and the generation of PAH clusters. Calcination at $750{ }^{\circ} \mathrm{C}$ produces an intense $\mathrm{C} 1 \mathrm{~s}$ resonance at $285.1 \mathrm{eV}$ characteristic of a delocalized graphitic $\mathrm{sp}^{2} \mathrm{C}-\mathrm{H}$ and $\mathrm{C}-\mathrm{C}$ and a 
<smiles>O=c1cc[nH]c2cc3nc4c(cc[n+]5ccccc45)cc3cc12</smiles>

\section{Scheme 1. Hypothetical graphenic carbon fragment illustrating local nitrogen structures: (left) pyridonic (such equilibria may also involve oxygen ortho to nitrogen), (middle) pyridinic, and (right) aromatic quaternary [74].}

smaller components at $289.5 \mathrm{eV}$ emanating from $\pi^{*}-\pi$ shake-up [70] and further delocalization and at $286.9 \mathrm{eV}$ characteristic of $\mathrm{C}-\mathrm{OH}$. The $\mathrm{N} 1 \mathrm{~s}$ signal becomes split into a dominant aromatic quaternary at $401.2 \mathrm{eV}$ and a pyridinic nitrogen signal at $398.5 \mathrm{eV}$ (Scheme 1). FTIR spectra (Fig. S5) show a distinct $\mathrm{OH}$ resonance centered at $3450 \mathrm{~cm}^{-1}$ and a very small $\mathrm{C}-\mathrm{H}$ stretching signal at $2930 \mathrm{~cm}^{-1}$. A distinct and broad band at $1120 \mathrm{~cm}^{-1}$ is assigned to C0 stretching $(\mathrm{C}-\mathrm{OH})$.

XPS measurement results for hydrothermally treated glucoseamine, and for the resulting calcined material GlucNH $\mathrm{H}_{2}$ were somewhat similar (Table S1 and Fig. S4) to those mentioned above for the chitosan transformations, except that the oxygen contents and nitrogen contents after treatment at $750{ }^{\circ} \mathrm{C}$ were slightly smaller. The dominant $\mathrm{C} 1 \mathrm{~s}$ peak in glucoseamine $(\mathrm{HCl})$ was at $284.6 \mathrm{eV}$ from $\mathrm{C}-\mathrm{H}$ and $\mathrm{C}-\mathrm{C}$ carbons with a smaller resonance at $286.8 \mathrm{eV}$ for $\mathrm{C}-\mathrm{OH}$. N1s signals characteristic of amine $(398.5 \mathrm{eV})$ and of protonated amine $(400.5 \mathrm{eV})$ were observed. Hydrothermal carbonization resulted in a dominant $\mathrm{C} 1 \mathrm{~s}$ peak remaining at $284.6 \mathrm{eV}$, indicating persistence of $\mathrm{C}-\mathrm{C}$ and $\mathrm{C}-\mathrm{H}$ with some aromatic carbon formation and C-OH at $287.0 \mathrm{eV}$. The $\mathrm{N} 1 \mathrm{~s}$ signals shift to $399.3 \mathrm{eV}$, and are assigned 
to pyridinic nitrogen and $401.3 \mathrm{eV}$ for quaternary nitrogen. Calcination causes the main $\mathrm{C} 1 \mathrm{~s}$ peak to shift to $285.1 \mathrm{eV}$ (C-H, C-C sp ${ }^{2}$ aromatic) with $\pi^{*}-\pi$ shake-up at $290.0 \mathrm{eV}$ and some $\mathrm{C}-\mathrm{OH}$ at $287.1 \mathrm{eV}$. These aspects indicate extended delocalization of the $\pi$ system. While the morphology does not change as dramatically on post-HTC treatment at $750{ }^{\circ} \mathrm{C}$, the interlayer spacing becomes less broadened with increasing high temperature treatment [70]. The N1s spectrum becomes pyridinic at $398.5 \mathrm{eV}$ and aromatic quaternary at 401.2 $\mathrm{eV}$. As with Chitosan, the FTIR (Fig. S5) of $\mathrm{GlucNH}_{2}$ shows a weaker O-H stretch at 3450 $\mathrm{cm}^{-1}$ and no C-H stretching. Also a weaker broad band at $1120 \mathrm{~cm}^{-1}$ due to $\mathrm{C}-\mathrm{O}$ stretching is evident. Both of these materials exhibit significant nitrogen incorporation as graphitization is driven by higher temperature treatment. The pyridinic and pyridonic nitrogens reside at exterior or interior edges of PAH clusters. The graphitization in both materials is reflected by the presence of aromatic ( $C=C$ ) IR intensity centered approximately at $1600 \mathrm{~cm}^{-1}$ as is seen in graphene and graphene oxide materials [75].

The FurPVPI material has not been as extensively studied, but its XPS C1s and N1s spectra after calcination are illustrated in Fig. 2. The dominant carbon signal at $284.8 \mathrm{eV}$ is characteristic of aromatic carbon $(C=C)$. A much less intense resonance assigned to 286.9 $\mathrm{eV}$ is assigned to carbonyl, and a trace signal at $289.5 \mathrm{eV}$ indicates some ester carbonyl. The $\mathrm{N} 1 \mathrm{~s}$ spectrum has resonances of decreasing intensity at $398.5 \mathrm{eV}, 400.8 \mathrm{eV}$, and $400.2 \mathrm{eV}$ assigned, respectively, to (Scheme 1) pyridinic, pyridonic, and aromatic quaternary nitrogens. FTIR (Fig. S5) spectra indicate only trace hydroxyl stretching; no methylene stretching and only a small amount of C-O stretching at $1120 \mathrm{~cm}^{-1}$ can be seen. While slightly lower in oxygen and nitrogen than the Chitosan sample, this material exhibits similar morphology and high temperature graphitization, despite emanating from dramatically different starting materials.

C1s and N1s XPS spectra for calcined GlucMel are also shown in Fig. 2. The carbon spectrum shows a dominant aromatic $(\mathrm{C}=\mathrm{C})$ signal at $284.8 \mathrm{eV}$ and a shoulder at $286.9 \mathrm{eV}$ (assigned to carbonyl). Trace carbonyl ester is also seen at $289.5 \mathrm{eV}$. These signals are very similar to those for FurVPVI, except that the carbonyl shoulder is much more intense for GlucMel. The N1s spectrum for GlucMel is dominated by pyridinic nitrogen at $398.2 \mathrm{eV}$ and a strong shoulder at $400.2 \mathrm{eV}$ characteristic of quaternary aromatic nitrogen. These spectra 

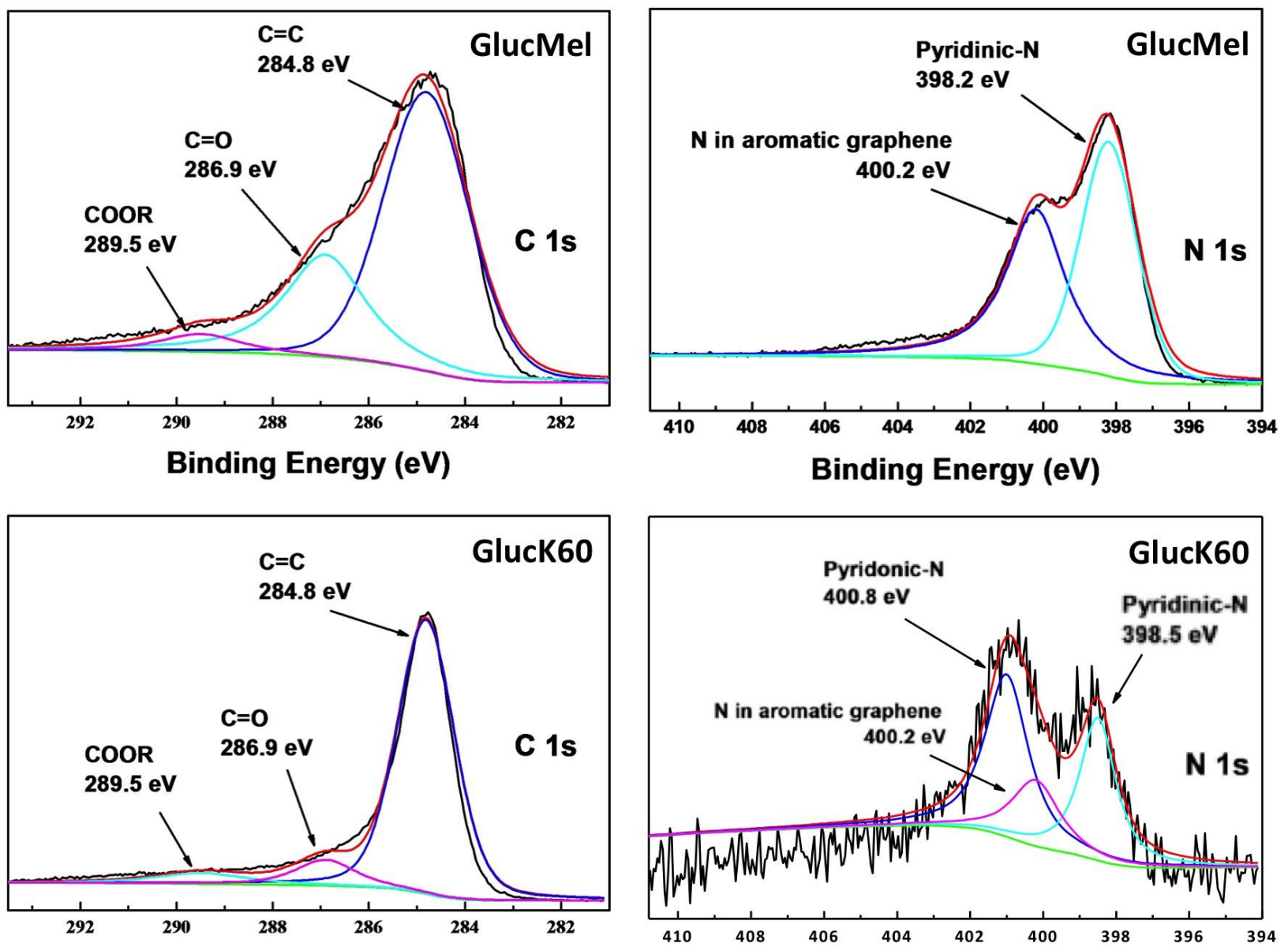

Binding Energy (eV)

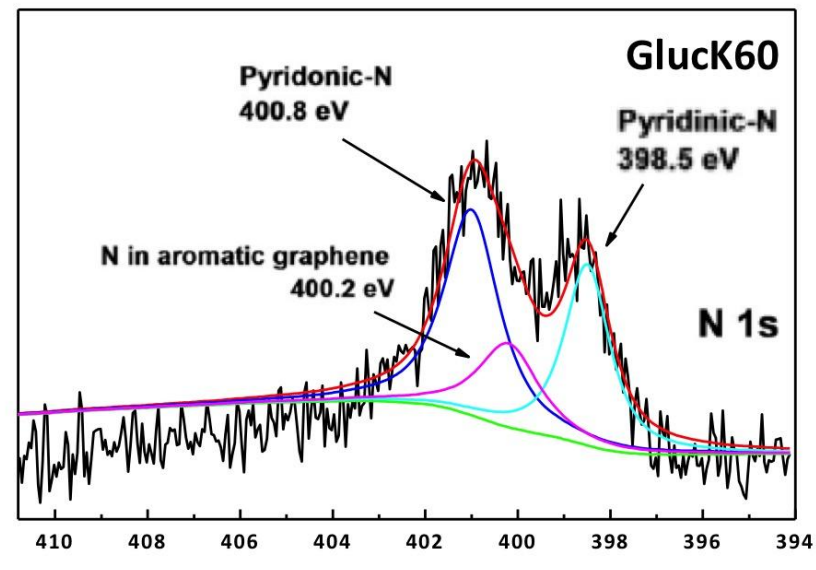

Binding Energy (eV)

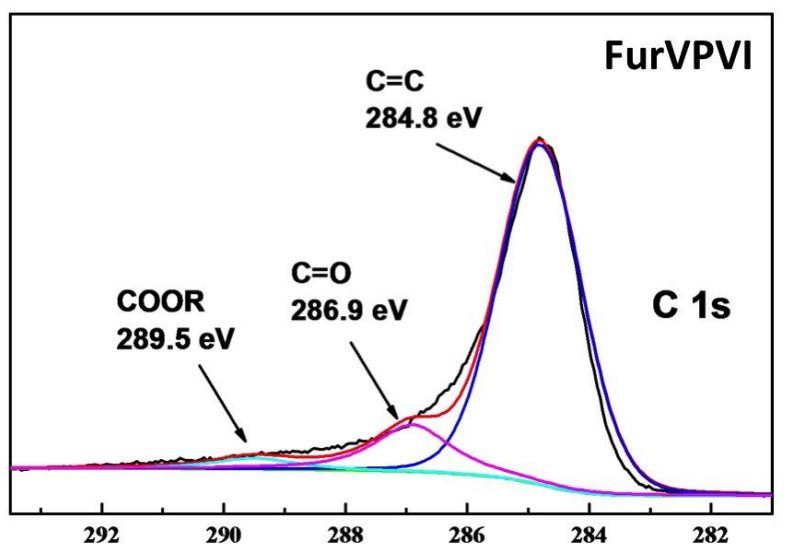

Binding Energy (eV)

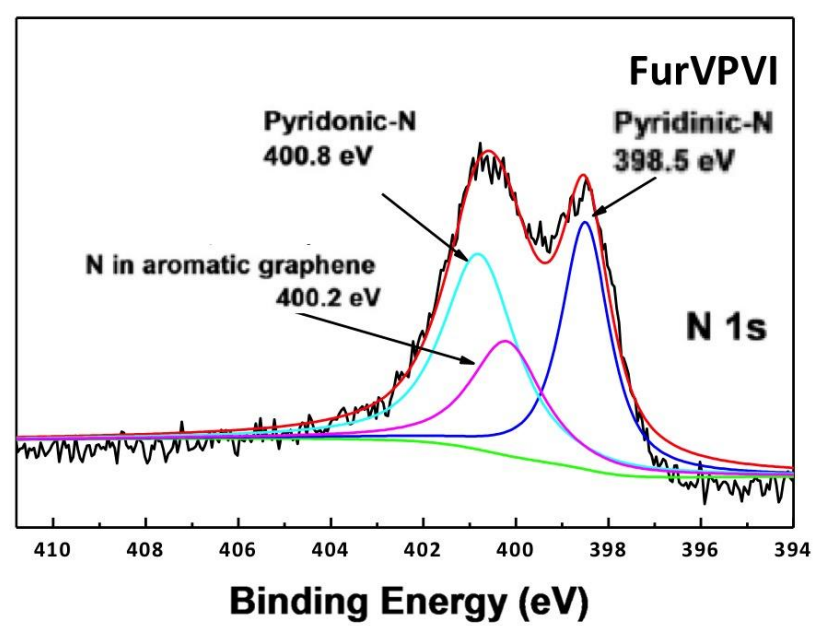

Fig. 2 - XPS spectra of GlucMel, GlucK60, and FurVPVI HTC/calcined samples (see SI for Chitosan and GlucNH $\mathrm{N}_{2}$ spectra published previously). 
show strong co-incorporation of carbon and nitrogen from glucose and melamine. FTIR spectroscopy shows a medium intensity hydroxyl stretching band at $3420 \mathrm{~cm}^{-1}$ (Fig. S5) but no methylene stretching resonance. This material exhibits broad and strong vibrations (Fig. S5) centered around $1600 \mathrm{~cm}^{-1}$ with a superimposed broad vibration at $1250 \mathrm{~cm}^{-1}$ that is very similar to spectra reported for layered carbon nitride related and $\mathrm{CN}$ heterocycle materials [76-78]. These vibrations emanate mainly from aromatic $\mathrm{C}=\mathrm{C}$ and $\mathrm{C}=\mathrm{N}$ stretching, and it appears graphitization of this material includes formation of carbon nitride-like domains.

The calcined GlucK60 material exhibits strong C1s XPS and weak N1s XPS in Fig. 2. The carbon spectrum is strongly dominated by the $284.8 \mathrm{eV}$ resonance of aromatic $\mathrm{C}=\mathrm{C}$ with only trace indications of carbonyl and ester carbonyl resonances at $286.9 \mathrm{eV}$ and $289.5 \mathrm{eV}$, respectively. The weakness of the $\mathrm{N} 1 \mathrm{~s}$ resonances at $398.5 \mathrm{eV}$ (pyridinic) and at $400.3 \mathrm{eV}$ (aromatic quaternary) can be attributed to the small amount of incorporated nitrogen (Table 2). FTIR shows weak $\mathrm{OH}$ stretching at $3450 \mathrm{~cm}^{-1}$ and weak $\mathrm{C}-\mathrm{O}$ stretching at $1120 \mathrm{~cm}^{-1}$. The $1500-1650 \mathrm{~cm}^{-1}$ resonance can be assigned to trace $\mathrm{C}=\mathrm{C}$ graphitic domains. This material very much transforms similarly to glucose as discussed above, but with incorporation of a small amount of nitrogen.

\subsection{Aqueous dispersions}

Our dispersion mixtures used an excess nanolatex to HTC ratio of about 8.8:1 by weight. This mixture was then subjected to low power sonication in an ultrasonic cleaning bath, followed by higher power sonication at $50 \%$ and $100 \%$ power amplitude for various times. Apparent optical density at $500 \mathrm{~nm}$ was tracked at the start and through this sonication process, and these optical densities are plotted in Fig. 3 as a function of sonication time. It is clear that the dispersibility of these HTC materials varies greatly.

The FurVPVI and Chitosan derived materials appear the least dispersible, while the GlucMel and GlucK60 materials appear the most dispersible. It has been seen in many dispersion studies of carbon nanotubes and graphene that an increase in apparent optical density in the visible is a marker of increased degree of dispersion [57,59,61], and the same appears to be the case here with HTC. 
When we compare the apparent optical density results of Fig. 3 with the SEM of Fig. 1 it is clear that the more porous looking HTC materials seen in Fig 1, GlucNH 2 , GlucMel, and GlucK60, are the most easily dispersed as depicted in Fig. 3. We therefore hypothesized that HTC material porosity is a trait that promotes ease of aqueous dispersibility by this sonication approach. To examine this hypothesis further, we examined thin films of these dispersions.

The mass weighted optical extinction of these HTC materials when dispersed is significant. The highest effective optical density illustrated in Fig. 3 is about 312 . When we consider that the mass concentration of that GlucK60 dispersion (and all of the dispersions) is $20 \mathrm{mg} / \mathrm{mL}$, we obtain an absorption coefficient at $500 \mathrm{~nm}$ of about 15.6 $\mathrm{cm}^{2} / \mathrm{mg}$. This value can be compared with values of $28.6 \mathrm{~cm}^{2} / \mathrm{g}$ for SWCNT [79] and about $50 \mathrm{~cm}^{2} / \mathrm{mg}$ measured for $1-5 \%(\mathrm{w} / \mathrm{w})$ graphene dispersions in water [61]. In those cases we are dealing with tubular or planar 2D graphenic carbon. This HTC extinction retains the mass weighting of the very large particulates, as we made no attempt to centrifuge these dispersions to remove large particles prior to sampling for apparent optical density.

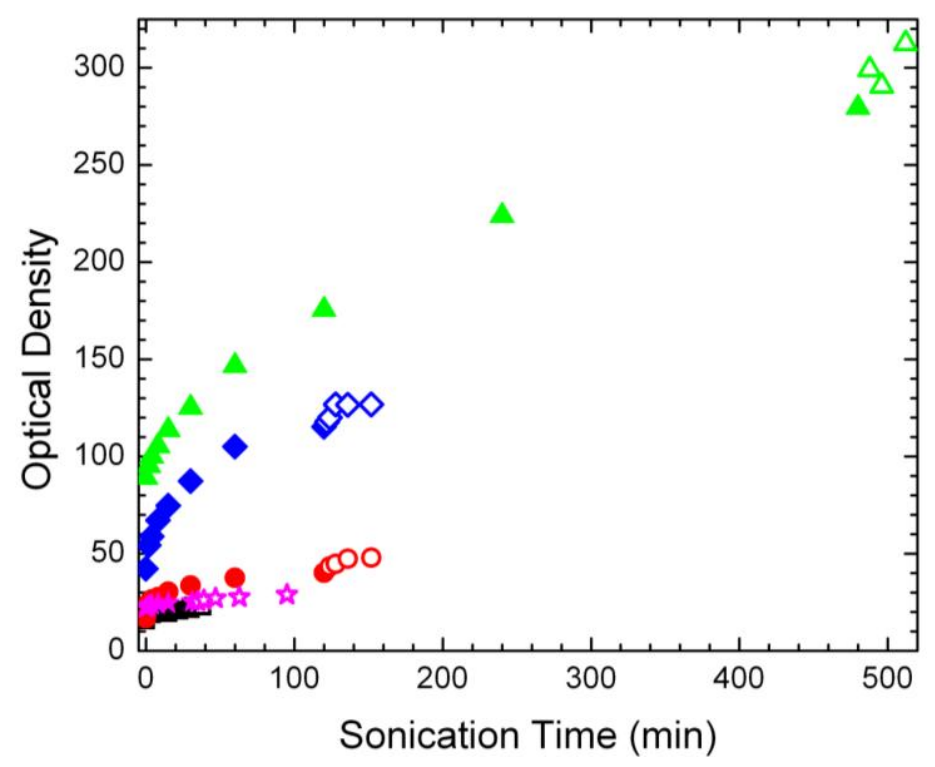

Fig. 3 -Effective dispersion optical density at $500 \mathrm{~nm}$ of HTC dispersions as a function of sonication time; Chitosan $(1, \bullet)$; $\operatorname{GlucNH}_{2}(\ominus, \bigcirc)$; GlucMel $(\diamond, \diamond)$; $\operatorname{GlucK60}(\triangle, \triangle)$; FurVPVI $(\square, \square)$; full symbols sonicated at $50 \%$ amplitude; open symbols sonicated at $100 \%$ amplitude. 
It seems probable that both the GlucK60 and GlucMel materials could be significantly further reduced in particle size with a corresponding increase in apparent optical density, since flat asymptotic behavior was not obtained. This is particularly the case for the GlucK60 sample, in view of its porosity (see later discussion).

\subsection{Particle size ranges observed in films}

Two types of films were prepared and analyzed by SEM for particle size ranges. Dispersions prepared as described earlier were sedimented for two hours at 3,000 rpm in a bench-top centrifuge. The supernatant was removed by aspiration, and the wet sediment was stirred vigorously and cast into a centrifuge tube cap and allowed to sediment and dry. Similarly, stirred dispersions were cast in such caps and allowed to sediment and dry overnight. After drying, these films were removed, chilled in liquid nitrogen, and freeze fractured for SEM analysis. Micrographs of these freeze fracture surfaces are illustrated in Fig. 4 (centrifuged sediment films) and Fig. 5 (dispersion films).

The Chitosan and FurVPVI sediments in Fig. 4 appear similar, and both exhibit very large particulates with dimensions greater than $20 \mu \mathrm{m}$ through the bottom (right most) two-thirds of the cross-sections illustrated. The GlucNH $\mathrm{H}_{2}$ and GlucMel sediments in Fig. 4 also have fairly large particles, and both also appear to have a smaller size fraction. The GlucK60 sediment in Fig. 4 clearly has a large volume fraction of particles smaller than evident in any of the other samples.

The cross-sections in Fig. 5 of the dispersion sediment all show an over-layer of predominantly coalesced nanolatex. These nanolatex over-layers appear devoid of particulates in the case of the Chitosan and FurVPVI dispersions, and particles with dimensions greater than $20 \mu \mathrm{m}$ are very evident in the sediment. The other three HTC materials exhibit particles in the nanolatex over-layers to varying degree. GlucNH $\mathrm{H}_{2}$ appears to have the fewest particles evident and the GlucMel material appears to have the most. The GlucK60 sample, however, has the smallest or thinnest nanolatex over-layer as well as 


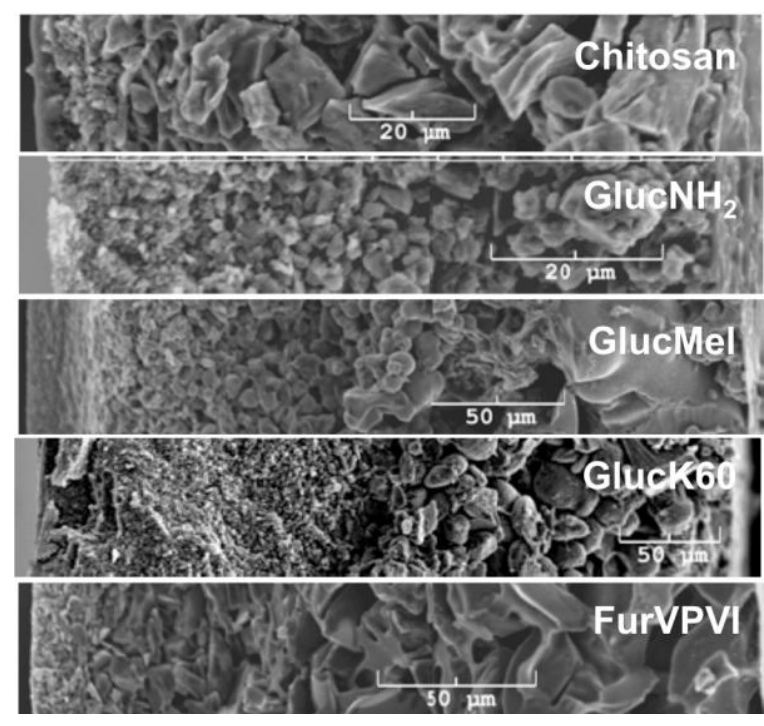

Fig. 4 - SEM of freeze fractured

sedimentation films obtained by centrifugation of HTC dispersions.
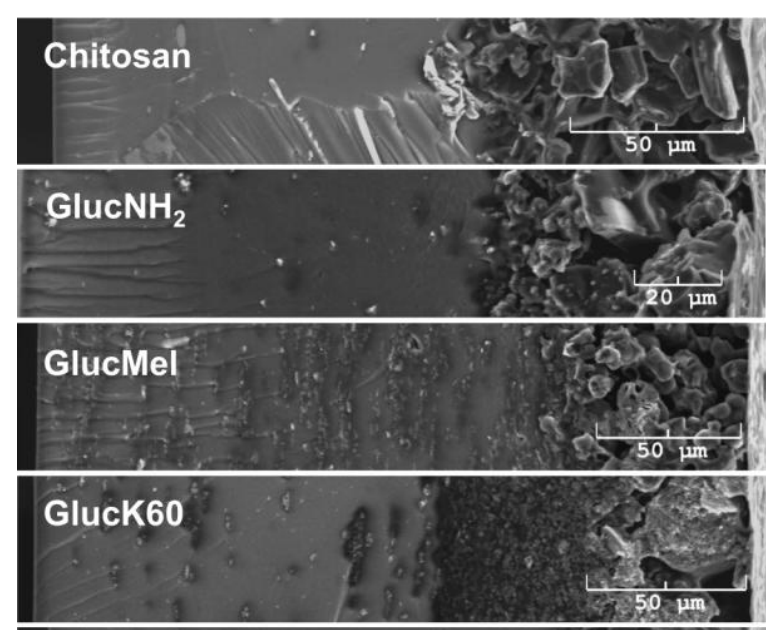

FurVPVi

Fig . 5 - SEM of freeze fractured thin film cross-sections of HTC dispersion films. The left extreme of the respective images corresponds to the top of the film and the right extreme corresponds to the bottom of the sedimentation bed (and film).

a substantially thick layer of fine particles, about the same thickness as the larger particles. The GlucK60 particles seen in the over-layer of nanolatex also appear in striated "layers", but to a much smaller extent than in GlucMel.

These analyses of SEM freeze-fracture cross-sections qualitatively show that the Chitosan and FurVPVI particle size ranges are the largest of the materials studied and have been influenced the least by our sonication procedures. It is also evident that the GlucK60 dispersion has the largest volume fraction of small particles and smallest volume fraction of large particles (Fig. 5), consistent with this material yielding the largest effective optical densities in Fig. 3.

\subsection{Porosity and friability}


Nitrogen adsorption measurements (Fig. 6) were done to establish experimental porosities [66] and BET (Brunauer Emmet Teller) specific surface areas [65] for these HTC materials prior to being dispersed. A summary of specific surface area and porosity data is given in Table 3, where we see that the Chitosan and FurVPVI materials have very low surface areas and porosities. These low porosity values indicate these samples are essentially devoid of pores, consistent with SEM examination.

The GlucNH $\mathrm{N}_{2}$ material is intermediate in porosity and specific surface area, $15.7 \mathrm{~m}^{2} / \mathrm{g}$, which indicates the presence of some macropores without any order, as well as in sample GlucMel $\left(57.2 \mathrm{~m}^{2} / \mathrm{g}\right)$. The GlucK60 material exhibits a relatively high surface area (> 300 $\mathrm{m}^{2} / \mathrm{g}$ ) formed of micropores and mesopores.

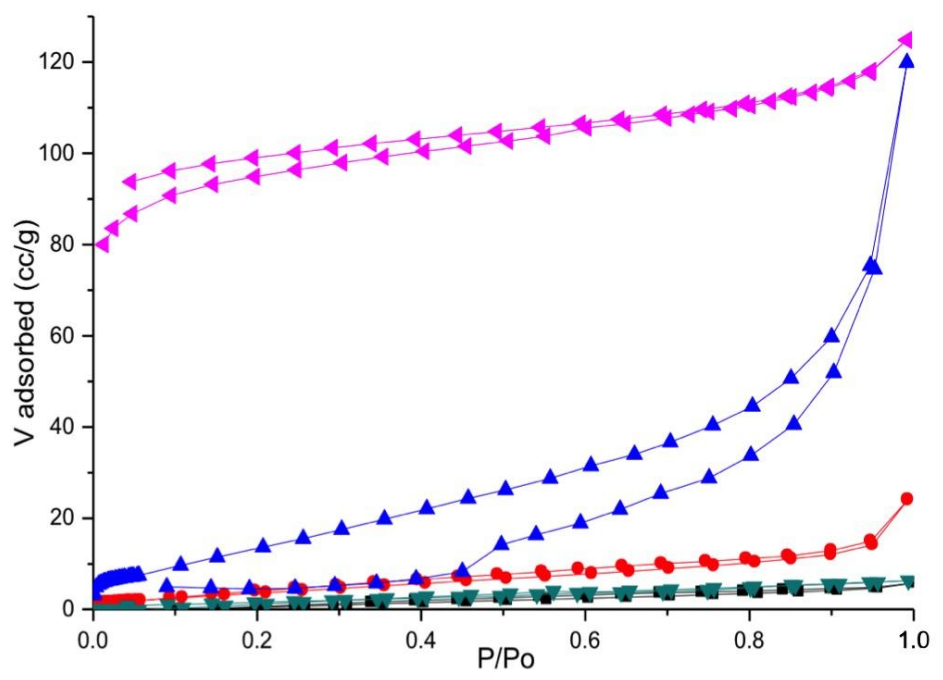

Fig. $6-\mathrm{N}_{2}$ sorption isotherms of Chitosan ( $\square$ ), GlucNH $(\bullet)$, GlucMel ( $\triangle$ ), FurPVPVI ( $\nabla$ ), and GlucK60 ( $>$ ).

These porosity and specific surface area values monotonically increase as functions of each other. When we take the largest effective optical density values for each material from Fig. 3 and plot these as a function of specific surface area for each material, we obtain the graph illustrated in Fig. 7. These data quantitatively confirm that ease of dispersibility increases with specific surface area (equivalently with porosity). 
Table 3 - Specific surface area and porosity of HTC materials

\begin{tabular}{ccc}
\hline HTC Precursor & $\begin{array}{c}\text { SET }_{\mathrm{BET}} \\
\left(\mathrm{m}^{2} / \mathrm{g}\right)\end{array}$ & $\begin{array}{c}\text { Pore Volume } \\
\left(\mathrm{cm}^{3} / \mathrm{g}\right)\end{array}$ \\
\hline Chitosan & 1.49 & 0.009 \\
GlucNH $_{2}$ & 15.7 & 0.037 \\
GlucMel & 57.2 & 0.11 \\
GlucK60 & 320 & 0.17 \\
FurPVPVI & 2.51 & 0.010 \\
\hline
\end{tabular}

We see that ease of dispersibility increases with friability (ease of fracturing solid into smaller particulates). The two most poorly dispersing materials, Chitosan and FurVPVI, have essentially no porosity. The two most easily dispersing materials, GlucK60 and GlucMel, have the highest measured porosity, and the intermediate material, $\mathrm{GlucNH}_{2}$, has intermediate porosity. These observations establish a link between porosity and friability for these HTC materials on $\mu \mathrm{m}$ to nm length scales.

Many studies of powders and compacts on larger length scales have shown that friability is linked to porosity through extensive studies of fracture mechanics [80]. Inman and co-workers showed that the critical stress intensity factor for microcrystalline cellulose compacts decreased exponentially with increasing porosity [81] as according to a proposition of Spriggs [82]. This link between porosity and friability has also been repeatedly demonstrated for compacted tablets in pharmaceutical applications $[83,84]$ and in fossiliferous brown coal processing [85]. This same link appears to exist for calcined HTC on smaller length scales.

It appears, therefore, that the correlation of Fig. 7 provides an empirical design criterion for forming sustainable calcined HTCs that can be transformed into waterborne dispersions. This design criterion relates to formulating for high porosity. Porous cells presumably are more susceptible to sonication-induced fracture. Such dispersions are useful for delivering micron to nanosize carbon particles for various applications, including printing, photothermal heating, inkjet writing of wiring (circuits and RFID), conventional composites, and as fuels for carbon fuel cells. 


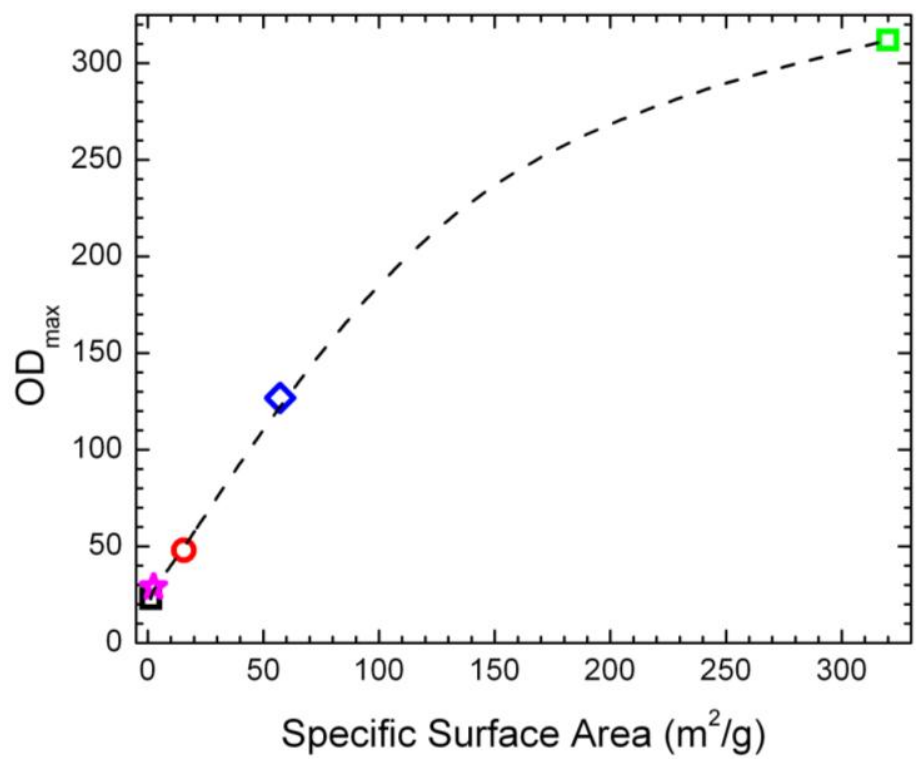

Fig. 7 - Correlation of asymptotic optical density ( $\left.O D_{\max }\right)$ achieved for each of the five HTCs studied (Chitosan, ^; GlucNH2, $\bigcirc$; GlucMel, $\diamond$; GlucK60, $\triangle$; FurVPVI, $\square$ ) after exhaustive sonication in our waterborne dispersion process as a function of the measured carbon specific surface area.

These qualitative observations are consistent with the respective $0 \mathrm{D}_{\mathrm{app}}$ and porosity (pore volume) values of Table 2 and a fracture model that emanates from porosity induced friability. We do not deny that variations in molecular structure induced by nitrogen doping may also affect friability, but there is no correlation of these optical or pore parameters with net nitrogen inclusion in these HTC samples.

\subsection{Dispersion stabilization}

The mechanism of dispersion stabilization of these HTC dispersions is likely very similar to that obtained for SWCNT [57], MWCNT [59], and graphene [61] dispersions. The imidazolium groups on the periphery of the nanolatex particles adhere strongly to HTC surfaces, particularly surfaces that may be termed $2 \mathrm{p}_{z}$ in nature. Such partially occupied 
atomic orbitals support delocalized $\pi$ systems on graphenic surfaces, and very likely similar bonding is found in calcined HTC, at least to some extent. Overlap between imidazolium $\pi$ bonds with partially filled $\pi$ orbitals on calcined HTC surfaces provide attractive adsorption interaction. The remaining parts of the adsorbed nanolatexes that also contain imidazolium bromide groups exhibit strong affinity for water. When adsorbed from suspension, as occurs in these experiments when the calcined HTC particulates are formed in the presence of a high concentration or nanolatex, the adsorbed coating of nanolatex provides a protective osmotic brush structure that exhibits excellent dispersion stability and a degree of imperviousness to fluctuating neutral salt concentration [86].

Some insight into the mechanism of nanolatex adsorption can be inferred from the SEM of Figs. 8 and 9. The nanolatex concentration in these dispersion preparations was quite high. It was about $16 \%$ to $18 \%(\mathrm{w} / \mathrm{w})$. We see that certain aspects of nanolatex adsorption are the same on both relatively smooth Chitosan surfaces as well on highly porous GlucK60 surfaces. The adsorption appears to be saturated; there does not appear to be sufficient empty space next to adsorbed nanolatexes for more adsorption. A similar phenomenon of saturation adsorption of nanolatex was observed on MWCNT surfaces [59]. In that case the adsorption appeared conformal, with some flattening occurring after adsorption.

Examination of higher magnification SEM, such as that of Fig. 9 for the Chitosan material, indicates that sufficiently closely adsorbed nanolatexes undergo surface coalescence, leading in some cases to what appears to be strings of adsorbed and partially coalesced particles. This micrograph illustrates in a clear way that adsorbed particles that have not undergone coalescence with neighboring particles are not necessarily spheroidal or circular in their project adsorbed area. This observation is consistent with TEM data of nanolatexes collected on carbon films that appear blotch-like rather than circular [60]. Many neighboring particles in Fig. 9 appear to have undergone coalescence involving two, three, four, and more particles. The reverse-S shaped string encircled in Fig. 9 by a dashed oval has a linear length of over $230 \mathrm{~nm}$ and is the most extensively coalesced object depicted in this image.

A statistical analysis of such saturation adsorption has been studied by Van Tassel and coworkers [85] analytically and in simulations. Their work goes beyond the random 
sequential adsorption (RSA) model where adsorption is considered random and irreversible, without subsequent conformational change. They included the possibility that once adsorbed, the macromolecular particle (modeled as a disk) could undergo conformational change, and spread (increase in radius) to some extent. This additional step results in the occupation by the adsorbed particle of more surface area than when initially

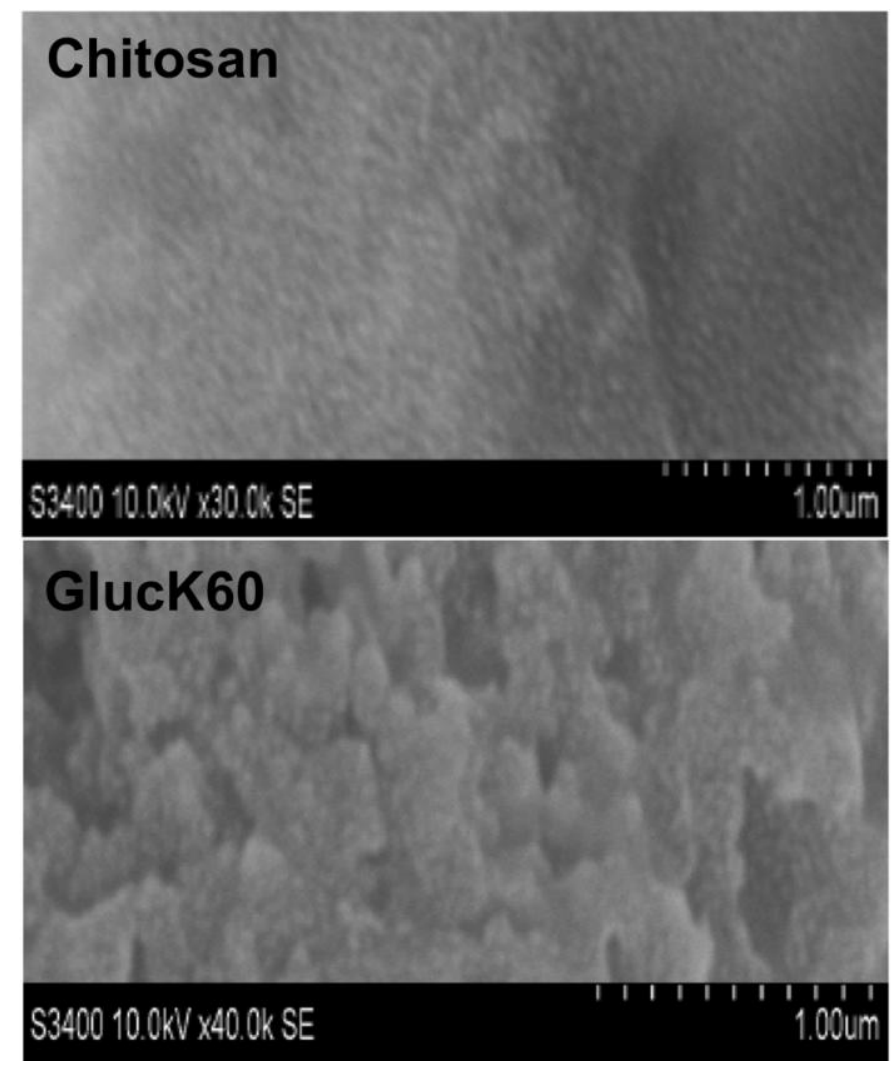

Fig. 8 - SEM of nanolatex saturation adsorption on (top) Chitosan and (bottom) Gluck60 HTC particles. The adsorbed nanolatex particles are slightly lighter than the underlying HTC surfaces.

adsorbed, and may also be viewed as a conformationally constrained additional wetting of the surface (driven by internal conformational changes and by particle surface interactions). Such pancaking was observed in FE SEM of nanolatex on MWCNT surfaces [59] as well where adsorbed nanolatexes are globular rather than disk-like. Also, surface coalescence was not so clearly seen. This difference may be due to a large difference in 
radii of curvature between these HTC surfaces imaged and the MWCNTs ( $\sim 20 \mathrm{~nm}$ radii) [59].

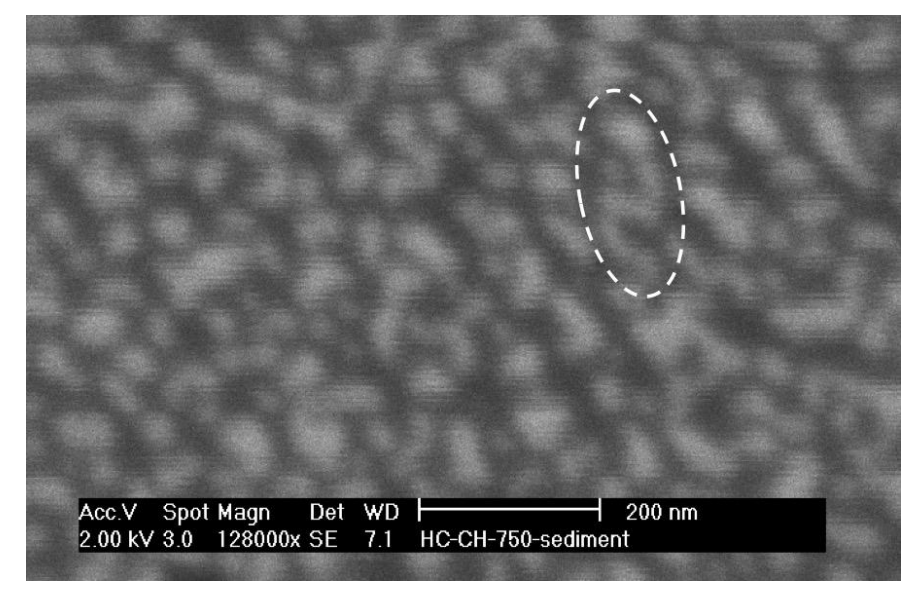

Fig. 9 - SEM of nanolatex near saturation adsorption on Chitosan HTC particle surface. A particularly long string of surface coalesced particles is encircled by the dashed oval in the upper right portion of the frame.

This extended RSA model of Van Tassel and coworkers [87] does not go quite far enough in admitting surface coalescence, but it does cover the important aspect of postadsorption spreading. Soft and deformable particles on surfaces, when sufficiently crosslinked can develop flat menisci between particles [88]. In this case the nanolatexes exhibit two behaviors: (1) they are not believed to be highly cross-linked, and given enough time in contact, appear to undergo "limited" coalescence or "surface coalescence;" (2) in certain cases certain parts of the interacting nanolatexes may be sufficiently cross-linked so that coalescence is impeded or blocked. The encircled example in Fig. 9 appears to exemplify both of these possibilities.

An analysis of the image of Fig. 9 indicates the fractional area occupied by adsorbed and surface coalesced nanolatex is 0.38 . This can be compared with a saturation area fraction of 0.547 in a "jamming" limit [89] for random sequential adsorption without post adsorption conformational change. In the random sequential models of Van Tassel and coworkers [87] this limit approaches 0.66, depending on the effective spreading amount and rate. This disparity raises two issues: (1) the data of Fig. 9 do not represent saturation; 
(2) oligomeric fractions that cannot be imaged cover sufficient "empty" area to block further adsorption. Possibility (1) differs from the simulations cited. Pre-adsorbed nanoparticles have finite heights, and can therefore retard subsequent adsorption of particles whose trajectories intersect elevated portions of pre-adsorbed particles. Possibility (2) is also a likely contributor, since the activated dispersion process of sonication induces scission of polymer backbone bonds, producing low molecular weight components that also have high adsorption affinity. These possibilities suggest both further experimental kinetic and saturation adsorption studies and modeling are needed.

\subsection{Electrical conductivity}

The sediment films illustrated in Fig. 9 were examined for their electrical conductivity in the plane of the film and perpendicularly through the film. Through-plane conductivity was measured by dielectric spectroscopy in the limit of low frequency and in-plane conductivity was measured using a four-probe surface conductivity set-up. Results are

Table 4 - Electrical conductivities through-pane $(\perp)$ and in-pane (II) for HTC sediment films

\begin{tabular}{ccc}
\hline HTC Precursor & $\begin{array}{c}\perp \\
(\mathrm{mS} / \mathrm{cm})\end{array}$ & $\begin{array}{c}\| \\
(\mathrm{mS} / \mathrm{cm})\end{array}$ \\
\hline Chitosan & 27 & $9.7 \pm 0.7$ \\
GlucNH & 9.4 & $3.9 \pm 0.9$ \\
GlucMel & 0.015 & $0.041 \pm 0.007$ \\
GlucK60 & 7.6 & $7.2 \pm 0.6$ \\
FurPVPVI & 7.4 & $4.1 \pm 0.8$ \\
\hline
\end{tabular}

summarized in Table 4 . Nanolatex control films at $25^{\circ} \mathrm{C}$ and $44 \%$ rh exhibit a through-film conductivity $(\perp)$ of $0.01 \mathrm{mS} / \mathrm{cm}$ and an in-plane conductivity (II) of $0.29 \pm 0.05 \mathrm{mS} / \mathrm{cm}$.

These electrical conductivities are substantial except for the GlucMel material. In both orientations, the Chitosan films exhibit the highest conductivity and the GlucMel films the lowest. Interpretation of these results should be done in the context of the sediment layer structures illustrated in Fig. 5 . The less than unity anisotropies $(I / / \perp)$ for the samples other 
than GlucMel are likely due to better contact with adjacent vertical strata due to gravitational sedimentation than with adjacent particles in the same strata. The GlucMel results appear of the same order as the nanolatex control coatings or smaller, suggesting that the GlucMel particles may be electrically insulating and blocking to current flow. This observation is supported by through-plane $\tan (\delta)$ spectra (not illustrated), where the GlucMel spectrum is very similar to the nanolatex control spectrum, while all the other spectra increase dramatically with decreasing frequency, as expected for highly conducting materials exhibiting electrode polarization. This low level of electrical conductivity is likely due to the much higher doping level of nitrogen in the GlucMel material, perhaps inducing out of plane defects in any graphitization.

The through-plane $(\perp)$ values appear larger than in-plane (II) except for the GlucMel material, and may result from tighter particle-particle contact emanating from sedimentation. The in-plane values have lower conductivities, and in any of the strata formed (Fig. 5), particle-particle contacts were not compressed by sedimentation.

\subsection{Thermal diffusivity}

Heat transfer was examined by measuring thermal diffusivities in circular sedimented films using xenon flash LFA 447 instrument. The measurements obtained are summarized in Table 5 for both shiny side illumination and matte side illumination. The matte side has the largest particulates and the shiny side has the smaller particles, since gravitational sedimentation was done normal to films and parallel to the shiny side to matte side direction. The through-plane values are uniformly small in the range of 0.21 to 0.34 , and two to four times the isotropic thermal diffusivity of the nanolatex control, $0.085 \mathrm{~mm}^{2} / \mathrm{s}$. The thermal diffusivities measured in-plane with matte sides illuminated are much, much higher, and range from 2.5 to $26 \mathrm{~mm}^{2} / \mathrm{s}$. Assuming a density of about $2 \mathrm{~g} / \mathrm{cm}^{3}$ and a heat capacity of about $0.6 \mathrm{~J} / \mathrm{g}$, these diffusivities range from a low of 0.25 to $31 \mathrm{~W} / \mathrm{m} / \mathrm{K}$. These higher values are 3 to 10 -fold the 2 to $10 \mathrm{~W} / \mathrm{m} / \mathrm{K}$ currently in use for nanoparticle/polymer composite adhesive and sealant applications requiring high thermal conductivity [90-92].

The GlucK60 sample, which exhibits the smallest particles and greatest porosity, appears to make the least thermally conductive films in-plane and has the smallest 
anisotropy. The 10-fold to 100-fold anisotropy, however, is understandable in terms of the distinct lateral layering we see in the sediments depicted in Fig. 9. The most interesting thing about these data is the rather large thermal diffusivity of the GlucMel material, essentially equivalent to that for the FurVPVI and Chitosan materials, in view of its very small, apparently insulating electrical conductivity listed in Table 3. Thus GlucMel, having an empirical formula approximately of $\mathrm{C}_{3} \mathrm{~N}_{5}$, may be a candidate for applications needing low electrical conductivity and high thermal conductivity.

The anisotropy of thermal diffusivity appears opposite that seen for electrical conductivity. The in-plane (II) values (Table 5) suggest larger particulates account for the higher thermal diffusivities observed, since direct irradiation (of matte sides) yields 2 to 5 fold higher values. The much lower through-plane values suggest thermal coupling between smaller particles provides a limiting thermal resistance.

Table 5 - Thermal diffusivities through-plane $(\perp)$ and in-plane $(I \mid)$ for HTC sediment films

\begin{tabular}{ccc}
\hline HTC Precursor & $\begin{array}{c}\perp \\
\left(\mathrm{mm}^{2} / \mathrm{s}\right)\end{array}$ & $\begin{array}{c}\| \\
\left(\mathrm{mm}^{2} / \mathrm{s}\right)\end{array}$ \\
\hline Chitosan & $0.26 / 0.27^{\mathrm{a}}$ & $8.3 / 23^{\mathrm{a}}$ \\
GlucNH & $0.33 / 0.35^{\mathrm{a}}$ & $2.5 / 13^{\mathrm{a}}$ \\
GlucMel & $0.21 / 0.22^{\mathrm{a}}$ & $6.6 / 24^{\mathrm{a}}$ \\
GlucK60 & $0.26 / 0.26^{\mathrm{a}}$ & $3.2 / 6.2^{\mathrm{a}}$ \\
FurPVPVI & $0.32 / 0.32^{\mathrm{a}}$ & $6.5 / 26^{\mathrm{a}}$ \\
\hline
\end{tabular}

a left/right - left value is with shiny (top) side of film irradiated with flash and right (bottom) is with matte side irradiated with flash.

\section{Conclusions}

Apparent optical density as a function of sonication dose provides an empirically sensible measure of dispersibility of HTC in water using nanolatex adsorption from suspension. The imidazolium moiety of the NL provides $\pi-\pi$ overlap bonding with 
graphenic surfaces presented by the HTC materials, and those moieties distal to the HTC surfaces are highly hydrated and provide osmotic brush dispersion stabilization. Dispersibility and friability increase monotonically with porosity, consistent with studies of powders and compacts prepared on larger length scales, establishing a practical link for the first time between dispersibility and porosity for carbon on tens of micron and smaller length scales.

A nitrogen-containing polymer, polyvinylpyrrolidone, in combination with glucose, yields the most highly friable HTC of the compositions evaluated in this study, GlucK60. The optical extinction of this material is competitive with that reported for SWCNT, despite the large volume fraction of large particles evident in GlucK60 after the maximum sonication treatment given in this study (Figs. 4 and 5). Such dispersions represent the possibility of producing useful suspensions at high volume suitable as conducting inks in microcircuit printing, inexpensive printing RFID (radio frequency ID) devices (replacing noble nanoparticle materials), electrically conducting composites, and thermally conducting coatings.

Surface (near) saturation by stabilizing nanolatex is imaged with scanning electron microscopy. These nanolatexes appear to adsorb by an apparently random and irreversible process that does not fully cover the substrate surface. Image analysis suggests saturation coverage slightly less than $40 \%$ (by area), in comparison to over $60 \%$ estimated from Monte Carlo studies of two-dimensional disks that increase their coverage after adsorption.

Sedimented films illustrate a very large range of particle sizes obtained during dispersion sonication. Further work is needed to better understand how nitrogen doping can be used to tune porosity in particular, and morphology in general, in HTC. Another of these new materials, GlucMel, appears an interesting layer-like material suited for applications requiring low electrical conductivity and high thermal conductivity, such as needed in refractory materials, and appears to be an interesting carbon nitride-like material.

\section{ACKNOWLEDGMENT}

This study was supported in part by Air Force Office of Scientific Research Grant Award No. FA9550-09-1-0431, Office of Naval Research Grant Award No. N00014-04-1-0763, and 
National Science Foundation Grant Award No. DMR-0414803, and by grants from the Max Planck Society. JT gratefully acknowledges the technical assistance of Rene Crombez, random sequential adsorption analyses discussions with Professor Zexin Zhang of Soochow University, and especially thanks Markus Antonietti for stimulating his interest in hydrothermal carbonization and advanced materials derived therefrom, and for suggesting an examination of the electrical conductivity of these materials.

\section{REFERENCES}

[1] Hu B, Wang K, Wu LH, Yu AH, Antonietti M, Titirici MM. Engineering carbon materials from the hydrothermal carbonization process of biomass. Adv Mater 2010;22:813828

[2] Antonietti M, Titirici MM. Hydrothermal carbonization of biomass: Black carbons with refined structure without charring . http://www.biocharinternational.org/images/Antonietti_ HTChouston2008.pdf, downloaded 17 February 2012.

[3] Shuttleworth PS, Budarin V, White RJ, Gun'ko VM, Luque R, Clark JH. Molecular-level understanding of the carbonization of polysaccharides. Chem Eur J 2013;19:93519357.

[4] Titirici MM, Antonietti M. Chemistry and materials options of sustainable carbon materials made by hydrothermal carbonization. Chem Soc Rev 2010;39:103-116.

[5] Kambo HS, Dutta A. A comparative review of biochar and hydrochar in terms of production, physico-chemical properties and applications. Renew Sustain Energy Revs 2015;45;359-378.

[6] Texter J, Crombez R, Titirici M, White R, Anotnietti M. Hydrothermal carbon for sustainable energy solutions. Prepr Pap-Am Chem Soc Div Energy Fuels 2012 ;57(2):628-629.

[7] Antal AA, Voge F, Lachance RP, Froeling M, Antal Jr MJ, Tester JW. Thermochemical biofuel production in hydrothermal media: A review of sub- and supercritical water technologies. Energy Environ Sci 2008;1:32-65. 
[8] Patel B, Guo M, Izadpanah A, Shah N, Hellgardt K. A review on hydrothermal pretreatment technologies and environmental profiles of algal biomass processing. Bioresource Technol 2016;199:288-299.

[9] Heilmann SM, Davis HT, Jader LR, Lefebvre PA, Sadowsky MJ, Schendel FJ, von Keitz MG, Valentas KJ. Hydrothermal carbonization of microalgae. Biomass Bioenergy 2010;34:875-882.

[10] Wang Q, Li H, Chen LQ, Huang XJ. Monodispersed hard carbon spherules with uniform nanopores. Carbon 2001;39:2211-2214.

[11] White RJ, Antoniettie M, Titirici MM. Naturally inspired nitrogen doped porous carbon. J Mater Chem 2009;19:8645-8650.

[12] Xia FJ, Pan M, Mu SC, Jones MD, Wolverson D, Marken F. Chitosan-based hydrothermal nanocarbon: Core-shell characteristics and composite electrodes. Electroanalysis 2012;24:1703-1708.

[13] Baccile N, Antonietti M, Titirici MM. One-step hydrothermal synthesis of nitrogendoped nanocarbons: Albumine directing the carbonization of glucose. ChemSusChem 2010;3:246-253.

[14] White RJ, Yoshizawa N, Antonietti M, Titirici MM. A sustainable synthesis of nitrogendoped carbon aerogels. Green Chem 2011;13:2428-2434.

[15] Yu LH,C, Weber J, White RJ, Howe JY, Titirici MM. Carbohydrate-derived hydrothermal carbons: A thorough characterization study. Langmuir 2012;28:12373-12383.

[16] Titiric MM, Thomas A, Antonietti M. Back in the black: hydrothermal carbonization of plant material as an efficient chemical process to treat the $\mathrm{CO}_{2}$ problem? New J Chem 2007;31:787-789.

[17] Vukcevic MM, Kalijadis AM, Vasiljevic TM, Babic BM, Lausevic ZV, Lausevic MD. Production of activated carbon derived from waste hemp (Cannabis sativa) fibers and its performance in pesticide adsorption. Microporous Mesoporous Mater 2015;214:156-165.

[18] Heilmann SM. Hydrothermal carbonization of microalgae. Biomass Bioenergy 2010;34:875-872.

[19] Kubo S, Demir-Cakan R, Zhao L, White RJ, Titirici MM. Porous carbohydrate-based materials via hard templating. ChemSusChem 2010;3:188-194. 
[20] Tian G, Gu ZJ, Liu XX, Zhou LJ, Yin WY, Yan L, Jin S, Ren WL, Xing GM, Li SJ, Jiao YJ. Facile fabrication of rare-earth-doped $\mathrm{Gd}_{2} \mathrm{O}_{3}$ hollow spheres with upconversion luminescence, magnetic resonance, and drug delivery properties. J Phys Chem C 2011;115:23790-23796.

[21] Du HM, Jiao LF, Wang, QH, Yang JQ, Guo LJ, Si YC, Wang YJ, Yuan NT. Facile carbonaceous microsphere templated synthesis of $\mathrm{Co}_{3} \mathrm{O}_{4}$ hollow spheres and their electrochemical performance in supercapacitors. Nano Res 2013;6:87-98.

[22] Zhao L, Bacsik Z, Hedin N, Wei W, Sun YH, Antonietti M, Titirici MM. Carbon dioxide capture on amine-rich carbonaceous materials derived from glucose. ChemSusChem 2010;3:840-845.

[23] Martin-Jimeno FJ, Suarez-Garcia F, Paredes JI, Martinez-Alonso A, Tascon JMD. Activated carbon xerogels with a cellular morphology derived from hydrothermally carbonized glucose-graphene oxide hybrids and their performance towards $\mathrm{CO} 2$ and dye adsorption. Carbon 2015;81:137-147

[24] Xiao PW, Guo D, Zhao L, Han BH. Soft templating synthesis of nitrogen-doped porous hydrothermal carbons and their applications in carbon dioxide and hydrogen adsorption. Micropor Mesopor Mater 2016;220:129-135.

[25] Yuan B, Wang J, Chen YX, Wu XF, Luo HM, Deng SG. Unprecedented performance of Ndoped activated hydrothermal carbon towards $\mathrm{C}_{2} \mathrm{H}_{6} / \mathrm{CH}_{4}, \mathrm{CO}_{2} / \mathrm{CH}_{4}$, and $\mathrm{CO}_{2} / \mathrm{H}_{2}$ separation. J Mater Chem A 2016;4:2263-2276.

[26] Guan ZR, Liu L, He LL, Yang S. Amphiphilic hollow carbonaceous microspheres for the sorption of phenol from water. J Hazard Mater 2011;196:270-277.

[27] Wang H, Ma LJ, Cao KC, Geng JX, Liu J, Song Q, Yang XD, Li SJ. Selective solid-phase extraction of uranium by salicylideneimine-functionalized hydrothermal carbon. J Hazard Mater 2012;229:321-330.

[28] Geng JX, Ma LJ, Wang H, Liu J, Bai CY, Song Q, Li J, Hou M, Li SJ. Amidoxime-grafted hydrothermal carbon microspheres for highlys Separation of uranium. J Nanosci Nanotech 2012;12:7354-7363.

[29] Liu YH, Wang YQ, Zhang ZB, Cao XH, Nie WB, Li Q, Hua R. Removal of uranium from aqueous solution by a low cost and high-efficient adsorbent. Appl Surface Sci 2013;273:68-74. 
[30] Zhang ZB, Nie WB, Li Q, Xiong GX, Cao XH, Liu YH. Removal of uranium(VI) from aqueous solutions by carboxyl-rich hydrothermal carbon spheres through lowtemperature heat treatment in air. J Radioanal Nucl Chem 2013;298:361-368.

[31] Yang XD, Li J, Liu J, Tian Y, Li B, Cao KC, Liu SB, Hou M, Li SJ, Ma LJ. Simple small molecule carbon source strategy for synthesis of functional hydrothermal carbon: preparation of highly efficient uranium selective solid phase extractant. J Mater Chem A 2014;2:1550-1559.

[32] Zhang ZB, Zhou ZW, Cao XH, Liu YH, Xiong GX, Liang P. Removal of uranium(VI) from aqueous solutions by new phosphorus-containing carbon spheres synthesized via one-step hydrothermal carbonization of glucose in the presence of phosphoric acid. J Radioanal Nucl Chem 2014;299:1479-1487.

[33] Li B, Ma LJ, Tian Y, Yang XD, Li J, Bai CY, Yang XY, Zhang S, Li SJ, Jin YD. A catechol-like phenolic ligand-functionalized hydrothermal carbon: One-pot synthesis, characterization and sorption behavior toward uranium. J Hazard Mater 2014;271:41-49.

[34] Yu XF, Liu YH, Zhou ZW, Xiong GX, Cao XH, Li M, Zhang ZB. Adsorptive removal of $\mathrm{U}(\mathrm{VI})$ from aqueous solution by hydrothermal carbon spheres with phosphate group. J Radioanal Nucl Chem 2014;300:1235-1244.

[35] Zhang WL, Zhang ZB, Cao XH, Ma RC, Liu YH. Uranium adsorption studies on hydrothermal carbon produced by chitosan using statistical design method. J Radioanal Nucl Chem 2014;301:197-205.

[36] Zhou ZW, Xiong GX, Liu YH, Cao XH, Zhang ZB. Removal of thorium(IV) from aqueous solutions by carboxyl-rich hydrothermal carbon spheres through low-temperature heat treatment in air. Desalin Water Treatment 2014;54:2516-2529.

[37] Demir-Cakan R, Makowski P, Antonietti M, Goettmann F, Titirici MM. Hydrothermal synthesis of imidazole functionalized carbon spheres and their application in catalysis. Cat Today 2010;150:115-118.

[38] Fraile JM, Garcia-Bordeje E, Roldan L. Deactivation of sulfonated hydrothermal carbons in the presence of alcohols: Evidences for sulfonic esters formation. J Catal 2012;289:73-79. 
[39] Pan KM, Ming H, Liu Y, Kong ZH. Large scale synthesis of carbon nanospheres and their application as electrode materials for heavy metal ions detection. New J Chem 2012;36:113-118.

[40] Zhang P, Li BB, Zhao ZB, Yu C, Hu C, Wu SJ, Qiu JS. Furfural-induced hydrothermal synthesis of ZnO@C gemel hexagonal microrods with enhanced photocatalytic activity and stability. ACS Appl Mater Interfaces 2014;6:8560-8566.

[41] Xu X, Tang MH, Li MM, Li HR, Wang Y. Hydrogenation of benzoic acid and derivatives over Pd nanoparticles supported on $\mathrm{N}$-doped carbon derived from glucosamine hydrochloride. ACS Catal 2014;4:3132-3135.

[42] Fraile JM, Garcia-Bordeje E, Pires E, Roldan L. Catalytic performance and deactivation of sulfonated hydrothermal carbon in the esterification of fatty acids: comparison with sulfonic solids of different nature. J Catal 2015;324:107-118.

[43] de la Calle C, Fraile JM, Garcia-Bordeje E, Pires E, Roldan L. Biobased catalyst in biorefinery processes: sulphonated hydrothermal carbon for glycerol esterification. Catal Sci Technol 2015;5:2897-2903.

[44] Roldan L, Pires E, Fraile JM, Garcia-Bordeje E. Impact of sulfonated hydrothermal carbon texture and surface chemistry on its catalytic performance in esterification reaction. Catalysis Today 2015;249:153-160.

[45] Ogino I, Suzuki Y, Mukai SR. Tuning the pore structure and surface properties of carbon-based acid catalysts for liquid-phase reactions. ACS Catal 2015;5:495-4958.

[46] Zhao L, Fan L-Z, Zhou M-Q, Guan H, Qiao SY, Antonietti M, Titirici MM. Nitrogencontaining hydrothermal carbons with superior performance in supercapacitors. Adv Mater 2010;22:5202-5206.

[47] Si WJ, Zhou J, Zhang SM, Li SJ, Xing W, Zhuo SP. Tunable N-doped or dual N, S-doped activated hydrothermal carbons derived from human hair and glucose for supercapacitor applications. Electrochim Acta 2013;107:397-405.

[48] Fan XM, Yu C, Yang J, Ling Z, Qiu JS. Hydrothermal synthesis and activation of graphene-incorporated nitrogen-rich carbon composite for high-performance supercapacitors. Carbon 2014;70:130-141. 
[49] Luo HX, Liu ZY, Chao LM, Wu XC, Lei XD, Chang Z, Sun XM. Synthesis of hierarchical porous $\mathrm{N}$-doped sandwich-type carbon composites as high-performance supercapacitor electrodes. J Mater Chem A 2015;3(7):3667-3675.

[50] Liu LC, Fan Q, Sun CZ, Gu XR, Li H, Gao F, Chen YF, Dong L. Synthesis of sandwich-like Ti02@C composite hokkow spheres with high rate capability and stability for lithium-ion batteries. J Power Sources 2013;221:141-148.

[51] Ye H, Yin YX, Xin S, Guo YG. Tuning the porous structure of carbon hosts for loading sulfur toward long lifespan cathode materials for Li-S batteries. J Mater Chem A 2013;1:6602-6608.

[52] Wang J, Zhao HL, Zeng ZP, Lv PP, Li ZL, Zhang TH, Yang TR. Nano-sized $\mathrm{Fe}_{3} \mathrm{O}_{4}$ /carbon as anode material for lithium ion battery. Mater Chem Phys 2014;148:699-704.

[53] Fraile JM, Garcia-Bordeje E, Pires E, Roldan L. New insights into the strength and accessibility of acid sites of sulfonated hydrothermal carbon. Carbon 2014;77:11571167.

[54] Li YB, Duan XB, Han YM, Zhu D, Huang LW, Chen YG. Sulfur-hydrothermal carbon composites for cathode in high-rate lithium-sulfur batteries. Chinese J Inorg Chem 2015;31:641-648.

[55] Zhang K, Qin FR, Lai YQ, Li J, Lei XK, Wang MR, Lu H, Fang J. Efficient fabrication of hierarchically porous graphene-derived aerogel and its application in lithium sulfur battery. ACS Appl Mater Interfaces 2016;8:6072-6081.

[56] England D, Tambe N, Texter J. Stimuli-responsive nanolatexes - Porating films. ACS Macro Lett 2012;1;310-314.

[57] Antonietti M, Shen Y, Nakanishi T, Manuelian M, Campbell R, Gwee L, Elabd YA, Tambe N, Crombez R, Texter J. ingle-wall carbon nanotube latexes. ACS Appl Mater Interfaces 2010;2(3):649-653.

[58] Texter J, Tambe N, Crombez R, Antonietti M, Giordano C. Stimuli responsive coatings of carbon nanotubes and nanoparticles using ionic liquid-based nanolatexes. Polym Mater Sci Eng 2010;102(1):401-402.

[59] Texter J, Ager D, Arjunan Vasantha V, Crombez R, England D, Maniglia R, Tambe N. Advanced nanocarbon materials facilitated by novel stimuli-responsive stabilizers. Chem Lett 2012;41:1377-1379. 
[60] Giordano C, Yang W, Lindemann A, Crombez R, Texter J. Waterborne WC nanodispersions. Coll Surf A 2011;374:84-87.

[61] Ager D, Arjunan Vasantha V, Crombez R, Texter J. Aqueous graphene dispersions Optical properties and stimuli-responsive phase transfer. ACS Nano 2014;8(11):11191-11205.

[62] Zhao L, Crombez R, Pérez Caballero F, Antonietti M, Texter J, Titirici MM. Sustainable nitrogen-doped carbon latexes with high electrical and thermal conductivity. Polymer 2010;51:4540-4546.

[63] Yan F, Texter J. Surfactant ionic liquid-based microemulsions for polymerization. Chem Commun 2006;2696-2698.

[64] England D, Yan F, Texter J. Porating anion-responsive copolymeric gels. Langmuir 2013;29:12013-12024.

[65] Brunauer S, Emmett PH, Teller E. Adsorption of gases in multimolecular layers. J Am Chem Soc 1938;60(2):309-319.

[66] Lastoskie C, Gubbins KE, Quirke N. Pore size distribution analysis of microporous carbons: A density functional approach. J Phys Chem 1993;97(18)4786-4796.

[67] Yu SH, Cui XJ, Li LL, Li K, Yu B, Antonietti M, Cölfen, H. From starch to metal/carbon hybrid nanostructures: Hydrothermal metal-catalyzed carbonization. Adv Mater 2004;16:1636-1640.

[68]Ryu JH, Suh YW, Suh DJ, Ahn DJ. Hydrothermal preparation of carbon microspheres from mono-saccharides and phenolic compounds. Carbon 2010;48:1990-1998.

[69] Li Z, Sustainable Approaches towards Novel Nitrogen-Doped Carbonaceous Structures. Thesis. Universität Potsdam, 2010.

[70] Li Z, Baccile N, Gross S, Zhang YJ, Wei W, Sun YH, Antonieti M, Titirici, MM. Sustainable nitrogen-doped carbonaceous materials from biomass derivatives. Carbon 2010;48:3778-3787.

[71] Pol VG, Thiyagarajan P. Measurement of autogenous pressure and dissociated species during the thermolysis of mesitylene for the synthesis of monodispersed, pure, paramagnetic carbon particles. Ind Eng Chem Res 2009;48:1484-1489. 
[72] Titirici MM, Antonietti M, Baccile N, Hydrothermal carbon from biomass: a comparison of the local structure from poly- to monosaccharides and pentoses/hexoses. Green Chem 2008;10:1204-1212.

[73] Falco C, Perez Caballero F, Babonneau F, Gervais C, Laurent G, TitiricYui MM, Baccile N. Hydrothermal carbon from biomass: Structural differences between hydrothermal and purolyzed carbons via ${ }^{13} \mathrm{C}$ solid state NMR. Langmuir 2011;27:14460-14471.

[74] McGann JP, Zhong MJ, Kim EK, Natesakhawat S, Jaroniec M, Whitacre JF, Matyjaszewski K, Kowalewski T. Block copolymer templating as a path to porous nanostructured carbons with highly accessible nitrogens for enhanced (electro)chemical performance. Macromol Phys Chem 2012;213:1078-1090.

[75] Si YC, Samulski ET. Synthesis of water soluble graphene. Nano Lett 2008;8:16791682.

[76] Bojdys MJ, Müller, JO, Antonietti M, Thomas. Ionothermal synthesis of crystalline, condensed, graphitic carbon nitride. Chem Eur 2008;14:8177-8182.

[77] Ma FW, Zhao H, Sun LP, Li Q, Huo LH, Xia T, Gao S, Pang GS, Shi Z, Feng AH. A facile route for nitrogen-doped hollow graphitic carbon spheres with superior performance in supercapacitors. J Mater Chem 2012;22:13464-13466.

[78] Dai HZ, Gao XC, Liu EZ, Yang YH, Hou WQ, Kang LM, Fan J, Hu XY. Synthesis and characterization of graphitic carbon nitride sub-microspheres using microwave method under mild condition. Diamoond Related Mater 2013;38:109-117.

[79] Bahr JL, Mickelson ET, Bronikowski MJ, Smalley RE, Tour FM. Dissolution of small diameter single-wall carbon nanotubes in organic solvents?. Chem Commun 2001:193-194.

[80] Bowman KJ, Smith NJ. Presentation, Fracture and mechanical properties of porous body compacts. 21 September 2006, www.ipph.purdue.edu/peck/2006/bowman.pdf, downloaded 17 May 2016.

[81] Inman SJ, Briscoe BJ, Pitt KG, Shiu C. Axial tensile fracture of microcrystalline cellulose compacts. Int J Pharm 2008;349:172-179.

[82] Spriggs RM. 1961. Expression for effect of porosity on elastic modulus of polycrystalline refractory materials, particularly aluminum oxide. J Am Ceram Soc 1961;44:628-629. 
[83] Gong XC, Sun CQC. A new tablet brittleness index. Eur J Pharm Biopharm 2015;93:260-266.

[84] Wikberg M, Alderborn G. Compression characteristics of granulated materials IV The effect of granule porosity on the compactibility of some granulations . Int J Pharma 1991;69:239-253.

[85] Guy PJ, Perry GJ. Victorian brown coal as a source of industrial carbons - A review. Fuel 1992;71(10):1083-1086.

[86] Pincus P. Colloid stabilization with grafted polyelectrolytes. Macromolecules 1991;14:2912-2929.

[87] Van Tassel PR, Viot P, Tarjus G, Talbot. Irreversible adsorption of macromolecules at a liquid-solid interface: Theoretical studies of the effects of conformational change. J Chem Phys 1994;101(8):7064-7063.

[88] Texter J, Bian D, Chojnowski D, Byrom J. Organosiloxane supramolecular liquids Surface energy driven phase transitions. Angew Chemie Int Ed 2013;52:2511-2515.

[89] Feder J, Giaver I. Adsorption of ferritin. J Colloid Interface Sci 1980;78(1):144-154.

[90] Ebadi-Dehaghani H, Nazempour M. Chapter 23 - Thermal conductivity of nanoparticles filled polymers. In Smart Nanoparticles Technology, Hashim A, Ed. InTech (2012) pp 519-540. http://cdn.intechopen.com/pdfs-wm/35438.pdf, downloaded 29 May 2016.

[91] Masterbond Tech Spotlight. Thermally conductive epoxies optimize electronic assemblies. http://www.masterbond.com/system/files/whitepaper/Master_BondThermally-Conductive-Epoxies-Optimize-Electronic-Assemblies.pdf?download=1, downloaded 31 May 2016.

[92] SARCON® Thermal Interface Materials. http://www.fujipoly.com/usa/assets/files/Fujipoly 2015 Sarcon Catalog for web.pdf\#page=3, downloaded 31 May 2016. 
TOC Graphic

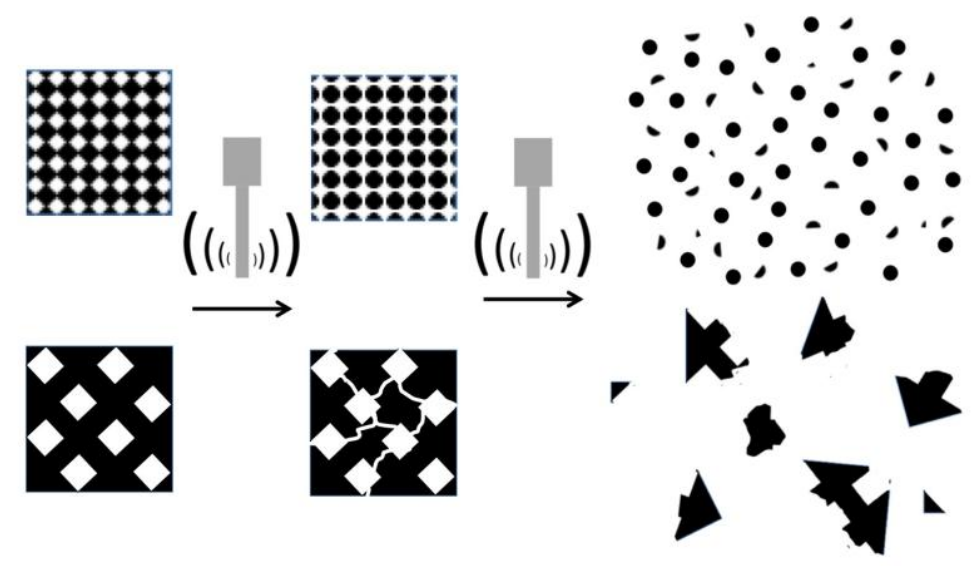

